\title{
Adult Hippocampal Neurogenesis, Fear Generalization, and Stress
}

\author{
Antoine Besnard ${ }^{1}$ and Amar Sahay ${ }^{\star 1,2,3,4}$ \\ ${ }^{1}$ Center for Regenerative Medicine, Massachusetts General Hospital, Harvard Medical School, Boston, MA, USA; ${ }^{2}$ Harvard \\ Stem Cell Institute, Harvard University, Cambridge, MA, USA; ${ }^{3}$ Psychiatric \& Neurodevelopmental Genetics Unit, \\ Massachusetts General Hospital, Boston, MA, USA; ${ }^{4}$ Department of Psychiatry, Massachusetts General Hospital, Harvard \\ Medical School, Boston, MA, USA
}

\begin{abstract}
The generalization of fear is an adaptive, behavioral, and physiological response to the likelihood of threat in the environment. In contrast, the overgeneralization of fear, a cardinal feature of posttraumatic stress disorder (PTSD), manifests as inappropriate, uncontrollable expression of fear in neutral and safe environments. Overgeneralization of fear stems from impaired discrimination of safe from aversive environments or discernment of unlikely threats from those that are highly probable. In addition, the time-dependent erosion of episodic details of traumatic memories might contribute to their generalization. Understanding the neural mechanisms underlying the overgeneralization of fear will guide development of novel therapeutic strategies to combat PTSD. Here, we conceptualize generalization of fear in terms of resolution of interference between similar memories. We propose a role for a fundamental encoding mechanism, pattern separation, in the dentate gyrus (DG)-CA3 circuit in resolving interference between ambiguous or uncertain threats and in preserving episodic content of remote aversive memories in hippocampal-cortical networks. We invoke cellular-, circuit-, and systems-based mechanisms by which adultborn dentate granule cells (DGCs) modulate pattern separation to influence resolution of interference and maintain precision of remote aversive memories. We discuss evidence for how these mechanisms are affected by stress, a risk factor for PTSD, to increase memory interference and decrease precision. Using this scaffold we ideate strategies to curb overgeneralization of fear in PTSD.

Neuropsychopharmacology Reviews (2016) 41, 24-44; doi:I0.1038/npp.20 I5.I67; published online 8 July 2015
\end{abstract}

\section{INTRODUCTION}

\section{A Circuit-Based Approach to Understanding the Neurobiology of PTSD}

The efficient processing of threatening and fearful stimuli is central to generation of adaptive behavioral and physiological responses. Inability to disambiguate safe from threatening stimuli or to calibrate physiological responses to uncertainty of threats can produce uncontrollable expression of fear, dysregulation of stress hormones, and sustained anxiety states. Exposure to traumatic events or stressful life experiences is known to tax our fear and threat processing systems. It is therefore not surprising that although the lifetime prevalence of generalized anxiety disorder (GAD) and posttraumatic stress disorder (PTSD) is between 5 and $10 \%$ in the general population (Newman et al, 2013; Parsons

${ }^{*}$ Correspondence: Dr A Sahay, Center for Regenerative Medicine, Massachusetts General Hospital, 185 Cambridge Street, CPZN 4242, Boston, MA 02114, USA, Tel: +1 617643 4371, Fax: 617724 2662,

E-mail: asahay@mgh.harvard.edu

Received 16 March 2015; revised 29 May 2015; accepted 5 June 2015; accepted article preview online 12 June 2015 and Ressler, 2013), the prevalence of PTSD is of greater magnitude in individuals repeatedly exposed to trauma (2030\%) (Catani et al, 2008; Parsons and Ressler, 2013). The relatively low prevalence of PTSD in the general population suggests that exposure to a severe traumatic event is not sufficient for its pathogenesis (Yehuda and LeDoux, 2007; Holmes and Singewald, 2013), but that genetic predisposition may be important. Seminal studies on monozygotic twins discordant for trauma exposure demonstrated that vulnerability to PTSD is explained in part (30-70\%) by genetic risk (Afifi et al, 2010; Pitman et al, 2012). More recently, singlenucleotide polymorphisms in genes encoding BDNF, the serotonin transporter SERT, and the glucocorticoid chaperone protein FKBP5 (Mahan and Ressler, 2012) have been associated with increased susceptibility to PTSD. These findings have been followed up with genome-wide analysis studies that have identified a plethora of putative culpable genes for PTSD (Cornelis et al, 2010; Koenen et al, 2013). Furthermore, alterations in epigenetic mechanisms may impair the adaptive regulation of gene expression that moderates vulnerability or resilience to stressful life events (Zovkic and Sweatt, 2013; Kwapis and Wood, 2014). Indeed, 
epigenetic modifications observed in PTSD patients are persistent (Malan-Muller et al, 2014) and, intriguingly, may be transmissible through the germline across generations (Yehuda et al, 2014; Dias et al, 2015). Thus, it is now recognized that PTSD arises from an interaction of environmental factors such as stressful, traumatic life events, and genetic risk factors.

Emerging neurobiology of PTSD suggests a role for both associative and nonassociative learning mechanisms (Lissek and van Meurs, 2014). Associative learning mechanisms are thought to underlie processes such as fear inhibition (Jovanovic and Ressler, 2010), extinction (Milad and Quirk, 2012), overgeneralization (Kheirbek et al, 2012b; Lissek, 2012), and memory consolidation and reconsolidation (Besnard et al, 2012; Nader et al, 2013; Parsons and Ressler, 2013). In addition, associative learning may also underlie time-dependent incubation and reorganization (Pitman et al, 2012) of memories to produce recurrent experiencing of traumatic events through flashbacks, nightmares, intrusive thoughts, and overgeneralization of fear (Pickens et al, 2009; Sauerhofer et al, 2012). On the other hand, nonassociative learning mechanisms are thought to contribute to sensitization, resulting in exaggerated startle responses to trauma-unrelated stimuli, hypervigilance, and increased avoidance behaviors (Pitman et al, 2012).

The contribution of environmental factors and potentially hundreds of genetic risk factors to development of PTSD underscores the challenges of developing new treatments. One approach to this problem is to instantiate the neural circuit-based mechanisms underlying associative and nonassociative learning-dependent processes theorized to occur in PTSD (Lissek and van Meurs, 2014). There are several reasons why this approach is likely to be therapeutically meaningful. First, neural circuits are the point of convergence for multitudinous genetic risk and environmental factors. Thus, measuring and targeting circuit performance is more tractable than targeting each of the putative genetic and environmental risk factors individually. Second, neural circuits of the hippocampus important for fear processing and anxiety are homologous between rodents (Gross and Canteras, 2012; Herry and Johansen, 2014; Luthi and Luscher, 2014; Tovote et al, 2015) and humans (Shin and Liberzon, 2010). The rich dialogue between studies probing causal roles of neural circuits underlying fear processing in preclinical models and human functional brain imaging is testament to the conservation of structure and function of neural circuits in posttraumatic psychopathology (Ressler and Mayberg, 2007; Holtzheimer and Mayberg, 2011; Milad and Quirk, 2012). Finally, characterization of circuit-based mechanisms permits generation of circuit basedendophenotypes that may be measured with high resolution and thus confer quantitative assessment and stratification of risk and treatment responses (Leboyer et al, 1998; Gottesman and Gould, 2003).

Here, we conceptualize fear generalization in terms of resolving interference between threats that are ambiguous or uncertain and previously encoded traumatic memories. We begin by familiarizing the reader with studies showing hippocampal involvement in resolution of interference and maintenance of precision of remote memories. (1) We hypothesize that pattern separation in the dentate gyrus (DG) plays a pivotal role in decreasing interference between ambiguous or uncertain threats and previously stored memories and in maintaining the precision of remote traumatic memories. (2) We discuss evidence supporting a role for the DG in pattern separation in rodents and humans before evaluating the contribution of adult-born dentate granule cells (DGCs) as neural substrates of pattern separation and orchestrators of temporal decay of precision of remote memories. (3) We invoke local circuit mechanisms by which adult-born DGCs influence pattern separation and the neural pathways that link encoding functions of adultborn DGCs with adaptive fear responses. (4) These sections set the stage for understanding how stress through its effects on adult hippocampal neurogenesis affects pattern separation to produce overgeneralization of fear. (5) We conclude by leveraging our framework about how adult-born DGCs contribute to pattern separation and maintain remote memory precision to ideate novel approaches to constrain overgeneralization of fear in PTSD.

\section{Hippocampal Interference, Ambiguous or Uncertain Threats, and Fear Overgeneralization}

In order to express fear only when it is appropriate, we have to constantly perform comparisons between previously encoded associations and what actually happens. Such a mechanism is adaptive in that it allows an individual to anticipate a potential threat by detecting relevant cues present in the environment. Efficient appraisal of threat requires disambiguation of contextual information associated with safety and threat as well as the discernment of the probability (certainty) with which a cue predicts the threat (Maren et al, 2013). Essential to this process is the need to decrease interference between new information and previously stored similar traumatic memories. Increased interference between new and stored memories will promote reactivation of traumatic memories and elicit inappropriate expression of fear resulting in fear overgeneralization.

Considerable evidence supports a role for the hippocampus in discrimination of similar contextual representations to constrain the overgeneralization of fear. Rats with anterograde dorsal hippocampal lesions exhibit normal levels of freezing in the conditioning context but are impaired in discriminating between similar contexts that are not associated with a foot-shock (Maren et al, 1997; Frankland et al, 1998; Antoniadis and McDonald, 2000). Genetically abolishing synaptic plasticity at perforant path-DG synapses impairs discrimination between a context in which mice were conditioned to a foot-shock and a similar, but not, distinct neutral context (McHugh et al, 2007). These behavioral studies allude to hippocampal-dependent mechanisms in minimizing interference between ambiguous 
threats (similar, neutral context) and stored memories (training context).

The hippocampus is also implicated in resolving interference between competing goals to gate approach-avoidance behaviors (Gray and McNaughton, 2000). This 'comparator' function permits resolution of uncertainty and unpredictability through risk assessment (signal of punishment, signal of nonreward, novelty, innate fear stimuli) by increasing vigilance and inhibition of motor functions (behavioral inhibition, arousal, attention) (Gray and McNaughton, 2000; Bannerman et al, 2014). Consistent with this proposal, unpredictable shocks in a given context retard subsequent acquisition of discrete cue-fear association in the same environment (Hinson, 1982; Foa et al, 1992). Imaging studies in humans have suggested a role for the hippocampus in processing uncertainty of threats. The anterior hippocampus (ventral hippocampus in rodents) was found to exhibit increased BOLD (blood oxygen level dependent) responses with uncertainty of probabilistic sequential events or unpredictable shock (Strange et al, 2005; Alvarez et al, 2011). Direct evidence for hippocampal engagement in encoding probabilistic cue-outcome associations comes from a study that performed in vivo recordings in the hippocampus of epileptic patients while they learned to associate cues with monetary rewards. The authors found that uncertainty of reward produced the largest event-related potentials in the anterior hippocampus (Vanni-Mercier et al, 2009). Together, these observations suggest that levels of interference in the hippocampus may contribute to resolution of uncertain or ambiguous threats to constrain fear overgeneralization.

\section{Hippocampal Interference, Time-Dependent Erosion of Memory Precision, and Fear Overgeneralization}

It is widely recognized that memories lose precision and details with passage of time. As such, traumatic memories when no longer bound by the conjunctive representation of the trauma will generalize to produce inappropriate expression of fear in contexts that are similar to that in which the trauma occurred. Consistently, fear generalization in contexts not associated with the shock is observed in rodents when the fear response is measured at remote time points (see, eg, Biedenkapp and Rudy, 2007; Wiltgen and Silva, 2007; Winocur et al, 2007; Ruediger et al, 2011). This unwanted cue-dependent recall of fear memory is thought to be due to changes in associative rather than nonassociative learning mechanisms (Acheson et al, 2012; Sauerhofer et al, 2012) and involves consolidation of memories in hippocampal-cortical networks.

Studies over the past two decades on the time-dependent reorganization and consolidation of episodic memories have generated tremendous insights into how loss of precision of remote aversive memories contribute to overgeneralization of fear in PTSD (Zola-Morgan and Squire, 1990; Squire and Zola-Morgan, 1991; Kim and Fanselow,
1992; Frankland and Bontempi, 2005; Wang and Morris, 2010; Wiltgen et al, 2010; Sutherland and Lehmann, 2011; Dudai, 2012; Goshen, 2014). The proposed roles of the hippocampus in time-dependent reorganization of memories have been influenced by the hippocampal memory index theory that posits a role for the hippocampus as an archive of indexes of neocortical engrams (Teyler and DiScenna, 1986; Teyler and Rudy, 2007). Specifically, episodes are encoded by strengthened connections between activated cortical ensembles and hippocampal indexes. Subsequent retrieval of memory within a subset of cortical neurons in the original trace and its corresponding hippocampal index reinstates the entire cortical trace. Thus, the hippocampal index is critical for reinstating and strengthening the cortical trace and decreasing interference with other cortical traces. As a consequence, interference between indexes (hippocampal ensembles) determines whether overlapping memory traces in the cortex are activated and the extent to which cortical traces are consolidated. The continued involvement of the hippocampus in maintenance of precision of remote contextual memories (Sutherland et al, 2008; Wang et al, 2009; Wiltgen et al, 2010; Goshen et al, 2011; Sparks et al, 2011) suggests that hippocampal-cortical system consolidation of remote memories may require the maintenance of hippocampal indexes.

Building on different theories of systems consolidation, the hippocampal index theory, and the general property of episodic memories to become more semantic with time (McClelland et al, 1995; Nadel and Moscovitch, 1997; Frankland and Bontempi, 2005; McKenzie and Eichenbaum, 2011), Hardt et al (2013) proposed that levels of interference in the hippocampus dictates the episodic-to-semantic shift in consolidated memories to influence time-dependent generalization. Specifically, a time-dependent decay of the hippocampal index would increase interference between overlapping cortical traces and render the memory less conjunctive and more semantic-like. This loss of episodic details in remote memories could induce overgeneralization of fear as fear is no longer constrained by conjunctive representation of the trauma and it is evoked by individual or elemental features of the traumatic context (Acheson et al, 2012). Conversely, this model predicts that decreasing interference in the hippocampus will slow down the decay of the hippocampal index over time and, consequently, ensure strengthening of the cortical trace and maintenance of the conjunctive representation and episodic details. In addition, we propose that increasing interference among cortical engrams would allow updating of the aversive memory trace by recruitment of trauma-unrelated cues whenever this trace is reactivated by its corresponding hippocampal index. This would result in unwanted expression of fear in response to trauma-unrelated cues, a key feature of PTSD. Thus, we propose that understanding the mechanisms that resolve interference in the hippocampus will edify (1) how uncertain or ambiguous threats are distinguished from past aversive memories and (2) how 
hippocampal indexes are maintained to influence timedependent generalization of fear. In the next two sections, we discuss evidence for neural mechanisms in the DG that contribute to resolution of interference in the hippocampus.

\section{Pattern Separation in DG Promotes Efficient Appraisal of Ambiguous and Uncertain Threats by Decreasing Interference}

One mechanism by which interference between new information (ambiguous and uncertain threats) and previously stored similar memories is minimized in the hippocampus is pattern separation in the DG-CA3 circuit (Treves and Rolls, 1992; McClelland and Goddard, 1996; Colgin et al, 2008). Computational models, guided by the connectivity of the hippocampus, have proposed a role for two complimentary operations, pattern separation and pattern completion, by which the hippocampus forms new episodic memories without interfering with those previously stored (Marr, 1971; McNaughton and Morris, 1987; O'Reilly and McClelland, 1994). Pattern separation is the process by which similar cortical inputs are made more distinct, thereby minimizing interference during storage, and is thought to require the DG (Treves and Rolls, 1992; McClelland and Goddard, 1996; Colgin et al, 2008). Pattern completion refers to the process by which a complete sequence of activity pattern is reinstated based on partial features of that pattern and is thought to require CA3 (O'Reilly and McClelland, 1994). Several distinct neuroanatomical features and physiological properties of the DG such as sparseness of activity and strong feed-back and feed-forward inhibition support its role in pattern separation (Jung and McNaughton, 1993; Freund and Buzsaki, 1996; Acsady et al, 1998; Gonzales et al, 2001; Chawla et al, 2005; Ramirez-Amaya et al, 2005; Tashiro et al, 2007). In contrast, the highly recurrent collaterals in CA3 serve the purpose of an associative network in which memories are stored within the network and can be retrieved even with partial inputs, facilitating pattern completion (Marr, 1971; McNaughton and Morris, 1987; Rolls, 1996; Nakazawa et al, 2002; Neunuebel and Knierim, 2014).

Studies examining the role of DG in resolving interference and pattern separation in rodents. Pioneering experimental studies in rodents probing the involvement of different hippocampal subregions in modulating interference have suggested a role for the DG in pattern separation (Kesner, 2013). Rodents with colchicine-induced ablation of the DG showed impaired discrimination of two spatial locations based on distal environmental cues, especially when there was large overlap of the distal cues, namely, spacing between the two locations was small (Gilbert et al, 2001). Consistent with these observations, genetic disruption of synaptic plasticity at perforant path-DG synapses in adult mice renders them inefficient discriminators of similar, but not distinct, contexts (McHugh et al, 2007). More recently, studies using optogenetic approaches have found that the DG also modulates interference of competing goals or contingencies. Optogenetic silencing of the dorsal DG in an active place avoidance task does not affect acquisition or retrieval of a stationary spatial location associated with a foot-shock in a rotating arena (Kheirbek et al, 2013). In this active avoidance task, the rotating platform continuously forces the animal to confront the original fear memory with the new rule by which the area no longer predicts a footshock. Interestingly, when the location of the shock zone is switched to the opposite side of the rotating arena, thereby necessitating resolution of two conflicting contingencies of a memory of a shock zone, optogenetic silencing of the dorsal DG impairs identification of the new shock zone (Kheirbek et al, 2013).

Electrophysiological recordings of place cells, internal representations of the external world, have instantiated a critical role for the DG and CA3 in pattern separation and pattern completion. By examining conditions under which place cells undergo remapping, either by changing their rate (rate remapping) or their rate and location (global remapping), various groups have found that subtle changes or parametric morphing of a rodent's environment elicits remapping of place cells in the DG (Leutgeb et al, 2007; Neunuebel et al, 2013; Neunuebel and Knierim, 2014). CA3 exhibits global remapping when the environment undergoes large changes, but place field is maintained even in the presence of degraded cues, reflective of pattern completion (Lee et al, 2004). Thus, tradeoff between pattern separation and pattern completion in CA3 relies on the extent of parametrical changes in the environment (Leutgeb et al, 2005; Neunuebel et al, 2013; Neunuebel and Knierim, 2014).

Cellular imaging approaches such as cellular compartment analysis of temporal activity by fluorescence in situ hybridization (catFISH) have permitted network-level examination of how the DG-CA3 circuit contributes to pattern separation and pattern completion. By tagging neurons using probes or genetic reporters that capture the timing of immediate early gene expression (IEG), it is possible to ascertain patterns of reactivation of neuronal ensembles over minutes or even weeks, and in response to specific contexts to probe global remapping. Such approaches have demonstrated that global remapping occurs in CA3 in situations of mismatch between two separate experiences, interpreted as pattern separation (Guzowski et al, 2004; Vazdarjanova and Guzowski, 2004; Schmidt et al, 2012a; Skinner et al, 2014). On the other hand, changing local cues in the environment leads to a modest remapping suggestive of a pattern completion mechanism in CA3 (Guzowski et al, 2004; Vazdarjanova and Guzowski, 2004). Consistent with electrophysiological studies, discrimination of similar contexts has been shown to elicit global remapping in the DG as well as in CA3 (Deng et al, 2013; Czerniawski and Guzowski, 2014). However, global remapping in the DG is not just observed during discrimination of contextual representations, instead resolving conflicting goals also engenders 
global remapping in the DG (Satvat et al, 2011; Schmidt et al, 2012b). Thus, pattern separation in the DG-CA3 circuit may constrain the overgeneralization of fear in ambiguous threatening contexts or when threat is uncertain. Consistent with this idea, two different studies using rodents have found that impaired discrimination between a similar, but not distinct, safe context and a fearful context is accompanied by impaired remapping of place cells in CA3 (McHugh et al, 2007; Czerniawski and Guzowski, 2014).

Studies examining the role of $D G$ in resolving interference and pattern separation in humans. Functional magnetic resonance imaging (fMRI) studies in humans have suggested a conserved role for the DG in pattern separation (Yassa and Stark, 2011; Deuker et al, 2014). In a landmark study, Bakker et al (2008) used fMRI in combination with an incidental encoding task in which subjects are presented a series of objects of varying similarity (Yassa and Stark, 2011). This task is predicated on the concept of repetition-suppression effect, that is, the response of a circuit adapts to repeated presentation of an object. Exploiting this concept of repetition-suppression, the authors found that the DG-CA3 circuit, rather than other regions of the medial temporal lobe, is most likely to be activated when object similarity is high. Furthermore, experiments in which BOLD fMRI was performed as mnemonic similarity was parametrically varied found that the DG-CA3 circuit showed greater activity than CA1 in response to subtle, but not large, changes in input (highly similar objects) (Lacy et al, 2011). Together, these data suggest that the DG in humans may perform input-output transformations similar to that seen in rodents (Leutgeb et al, 2007).

A crucial unanswered question is whether pattern separation in the DG is impaired in individuals with PTSD. Although a high-resolution structural MRI study found a selective reduction in volumes of DG and CA3 subfields in individuals with PTSD (Wang et al., 2010), how these structural changes affect pattern separation-completion balance in the DG-CA3 circuit is yet to be determined. One study measured physiological parameters (risk assessment and electromyography) in healthy subjects and individuals with PTSD as they were shown a series of images that morphed from a conditioned danger stimulus (large circle) associated with a finger shock into a smaller circle that was not associated with the shock (conditioned safety stimulus). In this task, healthy controls exhibited a steep decline in physiological responses as the conditioned danger stimulus was morphed into the safe stimulus indicative of efficient discrimination of ambiguous threats. Although the PTSD group exhibited increased sensitization to the conditioned stimulus, they also exhibited increased threat perception to the intermediate cues closest in similarity to the conditioned danger cue reflective of increased interference (Lissek and Grillon, 2012). Whether these generalization gradients engage pattern separation in the DG necessitates further studies that combine fMRI and incidental encoding.

\section{Pattern Separation in DG May Maintain Precision of Remote Fear Memories by Decreasing Cortical Interference}

As discussed in the section 'Hippocampal interference, time-dependent erosion of memory precision, and fear overgeneralization,' modulation of interference in the hippocampus may dictate the stability of the hippocampal index of neocortical memory representations, thereby promoting their consolidation and protecting them from the interference-dependent loss of episodic detail. Based on this idea, one would predict that decreased pattern separation in the DG would result in loss of memory precision at remote time points to increase time-dependent overgeneralization of fear (Hardt et al, 2013). In support of this hypothesis, recent cellular activity tagging studies showed that at remote time points, when mice generalize fear in novel, safe contexts, there is a decrease in global remapping in the DG and CA3 (Denny et al, 2014). Conversely, reinstating the cortical trace and potentially maintaining the hippocampal index by exposing mice to the training context before testing remote memory has been shown to maintain remote memory precision (Wiltgen and Silva, 2007; Wiltgen et al, 2010). Further studies are needed to determine whether there is a causal link between pattern separation in the DG and precision of remote memories.

\section{Adult Hippocampal Neurogenesis Modulates Pattern Separation to Resolve Conflict, Disambiguate Threats, and Maintain Precision of Remote Memories}

New DGCs are continuously generated from neural stem cells in the DG of hippocampus in humans and rodents throughout life (Altman and Das, 1965; Kaplan and Hinds, 1977; Cameron et al, 1993; Kuhn et al, 1996; Eriksson et al, 1998; Seri et al, 2001; Spalding et al, 2013). Anatomical and electrophysiological studies have demonstrated that adultborn DGCs functionally integrate into the neuronal network and that they exhibit heightened synaptic and structural plasticity during early stages of maturation (Zhao et al, 2008; Ming and Song, 2011; Aimone et al, 2014; Christian et al, 2014). Numerous studies have found that levels of adult hippocampal neurogenesis are highly sensitive to both aversive and enriching experiences and interventions (Ming and Song, 2011; Aimone et al, 2014; Ernst and Frisen, 2015; Opendak and Gould, 2015). Together, these observations suggest that the adult-born DGCs may act as substrates for experience-dependent neural circuit plasticity and may configure the DG in response to the animal's experiences and environments over its lifetime. Indeed, recent findings from studies in rodents suggest that rates of neurogenesis may contribute to emergence of individuality (Freund et al, 2013). 
The past two decades have witnessed tremendous experimental and theoretical investigation of the functions of adult hippocampal neurogenesis in cognition and multiple theories have been proposed (Aimone et al, 2014; Cameron and Glover, 2015) including pattern separation to modulate interference (Wiskott et al, 2006; Becker and Wojtowicz, 2007; Deng et al, 2010; Sahay et al, 2011a; McAvoy et al, 2014), cognitive flexibility (Kempermann, 2008; Burghardt et al, 2012), pattern integration (Aimone et al, 2010), encoding of temporal contexts (Aimone et al, 2006; Rangel et al, 2013), memory resolution (Aimone et al, 2011), decay of remote memories (Arruda-Carvalho et al, 2011; McAvoy et al, 2014; Wang et al, 2014), and forgetting (Frankland et al, 2013; Akers et al, 2014). Here, we discuss the evidence from studies in rodents implicating adult-born DGCs in modulation of interference in DG-CA3 circuit and articulate how adult hippocampal neurogenesis may constrain the overgeneralization of fear through pattern separation in the DG.

Modulation of spatial interference. Recapitulating the logic of pioneering studies implicating the DG in modulation of spatial interference (Gilbert et al, 2001), the impact of blocking adult hippocampal neurogenesis was assessed in a two-choice touch screen spatial discrimination task and a delayed nonmatching to place radial arm maze task to probe a mouse's ability to correctly distinguish closely or far spaced arms or objects (Clelland et al, 2009). In both tests, the correct choice that mice were required to make (selecting a new maze arm from one previously visited based on spaced distal room cues or choosing one of two boxes spaced apart on a touch screen with a nose poke) relied on discrimination of small or large spatial separations. Consistent with previous lesion studies of the DG, the authors found that blockade of adult hippocampal neurogenesis by $\mathrm{X}$-irradiation impaired the animal's ability to make fine, but not large, spatial discriminations. That is, hippocampal X-irradiated mice were not as efficient in discriminating between the choice and sample maze arms or boxes on the touch screen when they were close together, but not when spaced far apart. Studies using genetic approaches to ablate adult hippocampal neurogenesis in mice and rats have produced ambiguous results in the radial arm maze (Pan et al, 2012b; Groves et al, 2013; Zhang et al, 2014) and in the touch screen task (Swan et al, 2014). The basis for this incongruence across studies and between species is not clear, and may be because of differences in the experimental approaches used to ablate adult hippocampal neurogenesis (X-irradiation vs genetic approaches) and testing protocols.

The contextual fear discrimination learning task also enables assessment of the role of adult hippocampal neurogenesis in modulating spatial interference. As stated earlier, cellular imaging studies have found using this task that discrimination between similar contexts is accompanied by network-level mechanisms of pattern separation in the DG and CA3 such as global remapping (Niibori et al, 2012; Deng et al, 2013; Czerniawski and Guzowski, 2014). Blockade of adult hippocampal neurogenesis by genetic means or hippocampal-targeted X-irradiation or disruption of synaptic plasticity in adult-born DGCs impairs discrimination of a safe, similar context from the context associated with a foot-shock (Sahay et al, 2011b; Kheirbek et al, 2012a; Nakashiba et al, 2012; Niibori et al, 2012; Tronel et al, 2012; $\mathrm{Wu}$ and Hen, 2014). Consistent with these findings, $\mathrm{X}$-irradiation-dependent blockade of adult neurogenesis produced impairments in a visual discrimination water maze task only under conditions of high interference (Winocur et al, 2012). Conversely, we found that genetic enhancement of adult hippocampal neurogenesis by blockade of cell death of adult-born DGCs, or more recently by enhancing integration of adult-born DGCs, was sufficient to enhance discrimination between a shock-associated context and a similar, but not distinct, neutral context (Sahay et al, 2011b; McAvoy et al, 2014). Importantly, using catFISH we have found that enhancing the integration of adult-born DGCs increased global remapping in the DG only under conditions of high interference, namely, similar context but not low interference, that is, distinct context (McAvoy et al, 2014). Together, these studies suggest that adult-born DGCs may facilitate spatial discrimination and constrain fear overgeneralization by minimizing interference between overlapping contextual representations (Figure 1).

Resolution of conflicting contingencies and goals. As discussed in the section 'Pattern separation in DG promotes efficient appraisal of ambiguous and uncertain threats by decreasing interference,' impairments in pattern separation mechanisms that minimize interference between conflicting goals and contingencies may contribute to fear overgeneralization. Several studies have suggested that adult hippocampal neurogenesis mediates cognitive flexibility by minimizing proactive interference (Wiskott et al, 2006; Becker and Wojtowicz, 2007; Kempermann, 2008). Reversal learning using the Morris water maze in which an animal must learn the new location of a hidden platform or using a touch screen task or an active place avoidance task is one way of probing proactive interference and cognitive flexibility. Studies using X-irradiation (Wojtowicz et al, 2008), chemical (Garthe et al, 2009), genetic (Pan et al, 2012b), or pharmacogenetic (Zhang et al, 2008, 2014) approaches to block adult hippocampal neurogenesis have consistently found perseveration in the original platform location at the expense of spending time in the new location, reflective of proactive interference (Garthe and Kempermann, 2013). Similar impairments in cognitive flexibility were observed following genetic ablation of adult hippocampal using an active place avoidance task (Burghardt et al, 2012) or a touch screen task (Swan et al, 2014). Conversely, we found using a novel strategy that enhancing the integration of adult-born DGCs decreased proactive interference in reversal learning using the Morris water maze (McAvoy et al, 2014). Whether these behavioral effects of titrating levels of adult hippocampal neurogenesis on cognitive flexibility and proactive interference engage pattern separation mechanisms in the DG remains to be determined. 
a

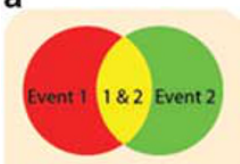

Population coding

b

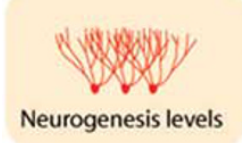

C

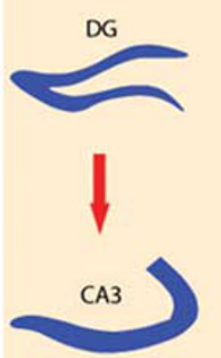

d

OUTCOME

Ensemble level e

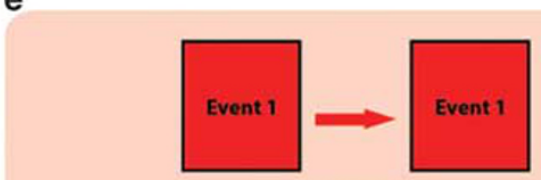

RE-EXPOSURE

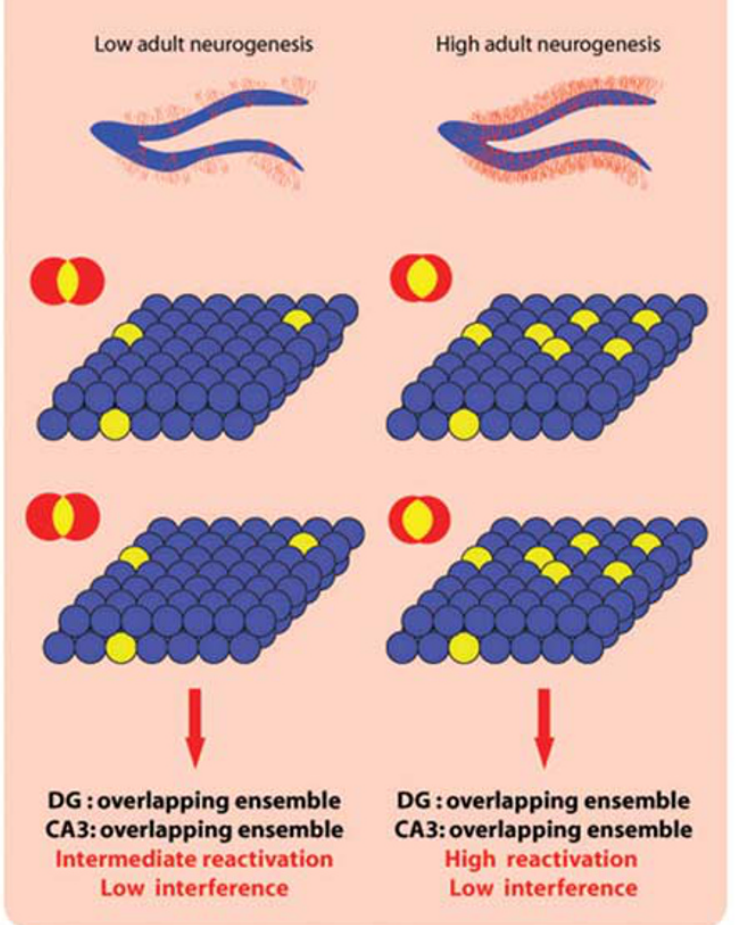

f

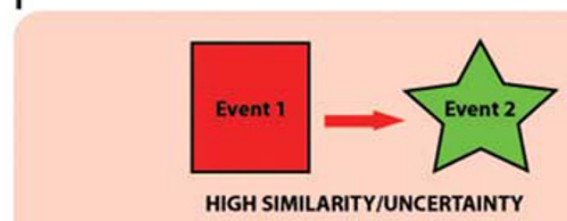

HIGH SIMILARITY/UNCERTAINTY

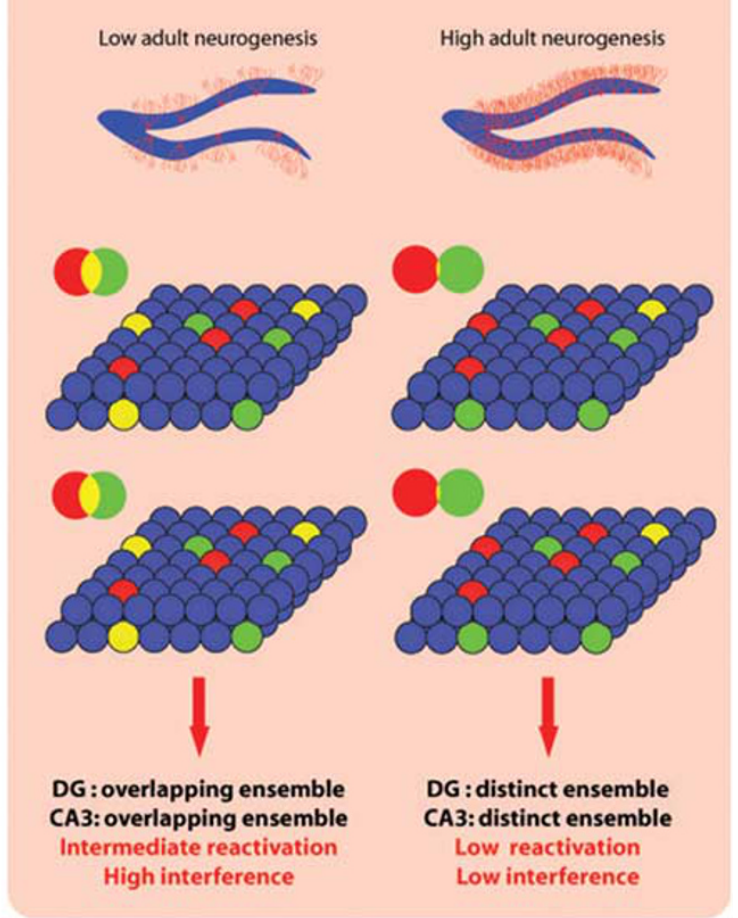

Figure 1. Adult hippocampal neurogenesis dictates population-based coding to gate memory reactivation and interference in DG-CA3. (a) Schematic representation of population-based coding of two separate events in DG and CA3. Neurons encoding event 1 are shown in red and event 2 in green. Neurons reactivated in response to repeated exposure of event 1 or event 2 are shown in yellow. Event 2 has high similarity with event 1 or may convey uncertainty of threat. (b) For each condition (reexposure of event 1 or event 1 followed by event 2), population coding is shown for high and low levels of adult hippocampal neurogenesis. (c) Schematic of engram in DG and CA3 under conditions of low and high adult hippocampal neurogenesis. (d) Outcome at network/population level. (e) When an event is re-encountered, greater reactivation of DGCs and CA3 neurons is seen with high levels of adult hippocampal neurogenesis (more yellow cells) and the converse is seen with low levels of adult hippocampal neurogenesis (fewer yellow cells). This may explain why enhancing adult hippocampal neurogenesis promotes memory persistence. (f) When there is interference because of similarity between two experiences or because of uncertainty of contingencies, high level of adult hippocampal neurogenesis promote population-based coding (global remapping) in the DG and CA3 (fewer yellow cells) to resolve interference. This orthogonalization of ensembles in DG and CA3 may prevent proactive interference and time-dependent decay in memory precision.

Although experimental evidence supporting a role for encoding uncertainty or unpredictability of threats is currently lacking, a recent study found using in vivo recordings of place cells in the DG that levels of adult hippocampal neurogenesis influence encoding of temporally separated exposures to a context in nonoverlapping ensembles of DGCs (Rangel et al, 2014). It is plausible that such a mechanism may minimize interference between cues associated with predictable and unpredictable contingencies to govern adaptive fear responses to uncertain threats. Together, these studies suggest a role for adult hippocampal neurogenesis in modulating proactive interference to promote conflict resolution when threats are ambiguous or uncertain (Figure 1).

Adult hippocampal neurogenesis and maintenance of memory precision. As discussed in the preceding sections, theoretical proposals and preliminary experimental evidence suggests that maintaining hippocampal indexes and modulating interference in the DG moderates the time-dependent erosion of memory precision. One mechanism by which hippocampal indexes may be maintained is by preventing their decay. Several lines of evidence from genetic loss-offunction and gain-of-function studies compellingly implicate adult hippocampal neurogenesis in the maintenance of remote memories and prevention of their decay. Genetic ablation of adult-born DGCs that were present during training in the contextual fear conditioning or spatial learning tasks resulted in degradation of the memory when the mice were tested shortly after training, suggesting that adult-born DGCs are substrates of the memory trace (Arruda-Carvalho et al, 2011). Furthermore, blocking adult hippocampal neurogenesis by genetic ablation of extracellular signal-regulated kinase 5 (ERK5) in neural stem cells 
and progenitors in the adult DG before, or immediately after, contextual fear conditioning increased the decay of remote memory, arguing for a role for adult-born DGCs in modulating memory persistence (Pan et al, 2012a). These studies corroborate an early report that used whole-brain irradiation to ablate adult hippocampal neurogenesis in rats before training and observed decreased remote spatial memory (Snyder et al, 2005). Conversely, genetic activation of ERK5 signaling in adult-born DGCs enhanced memory strength at remote time points in the novel object location, novel object recognition, and Morris water maze spatial learning tasks (Wang et al, 2014). Consistent with these observations, we have found that genetically enhancing integration of adult-born DGCs is sufficient to enhance remote contextual fear memory (McAvoy et al, 2014). One prediction from these studies is that time-dependent generalization of fear is decreased when decay of memory trace is slowed down by enhancing neurogenesis. Although blockade of adult hippocampal neurogenesis by elimination of ERK5 in neural stem cells and progenitors did not increase time-dependent generalization of fear in a novel context, the controls also failed to show an increase in freezing behavior to a novel context at remote time points in this study (Pan et al, 2012a). In contrast, posttraining ablation of adult-born DGCs present during encoding of a visual discrimination task impaired discrimination at remote time points (ArrudaCarvalho et al, 2011). Detailed analysis of the animal's swim patterns in this study suggested that elemental associations such as cue-platform location were maintained. This study supports the idea that neurogenesis-dependent modulation of interference may govern memory precision at remote time points by potentially preserving the conjunctive representation in the cortex. Such a mechanism would also constrain the erroneous updating of memories.

\section{Model for How Adult Hippocampal Neurogenesis Influences Pattern Separation In Dg to Govern Overgeneralization of Fear}

Building on the framework established in the preceding sections, we outline how levels of adult hippocampal neurogenesis dictate pattern separation in the DG to govern the overgeneralization of fear using the example of a traumatic memory of a bomb blast (Figure 2). An individual experiences a bomb blast in a café on a rainy day. The memory trace of this traumatic event is encoded in an ensemble of DGCs (pink circles in DG). This traumatic memory is consolidated as a conjunctive representation comprising a green trashcan, cup of coffee, umbrella, a red flower, and a bicycle within a cortical engram. The consolidated memory trace is made up of pink cortical neurons and corresponding pink DGCs serve as its hippocampal index (middle column, Figure 2). With normal levels of neurogenesis, the encoding of a new experience at a later time recruits a distinct ensemble of DGCs as a new hippocampal index (light blue circles in DG) through efficient pattern separation. Under these conditions, because of high global remapping in the DG, there is low interference, that is, overlap between the light blue DGCs and the pink DGCs that were recruited to encode the original traumatic memory (right column, Figure 2). This new (light blue DGCs) hippocampal index promotes the consolidation of this new representation within a cortical engram that is only partially overlapping with the cortical engram of the original traumatic memory. Although there is a natural timedependent decay of irrelevant features of the traumatic memory, many details are strengthened (red cells in cortex) within a conjunctive representation (red box). The second conjunctive representation of the new experience (blue box) develops without recruitment of trauma-related cues in the original memory (there is no updating). In contrast, decreased levels of adult hippocampal neurogenesis (left column, Figure 2) results in decreased global remapping and increased reactivation of some of the DGCs recruited to encode the original traumatic memory (overlap between light blue DGCs and pink DGCs), thereby increasing interference between the new similar experience and the original traumatic memory. Consequently, the hippocampal index for the new experience is made up of pink and light blue DGCs. Impaired pattern separation in the hippocampus will therefore result in coallocation of the new memory representation with the original representation in the neocortex (updating). The repetition of such a process over time accelerates the conjunctive to elemental shift in the original traumatic memory whose features are no longer bound within the cortical engram as a conjunctive representation (red box) (left column, Figure 2). As reactivation of a traumatic memory in similar, safe environments may arise because of excessive pattern completion, the combination of excessive pattern completion and impaired pattern separation in DG-CA3 circuit may create a closed loop permissive to persistent reactivations of traumatic memory and increased incorporation of trauma-unrelated cues into the cortical trace. Thus, the accelerated decay of conjunctive trace and incorporation of trauma-unrelated cues produces overgeneralization of fear. Consistent with these ideas, a recent study found a positive correlation between re-experiencing the traumatic event and the degree of fear overgeneralization in individuals with PTSD (Kostek et al, 2014).

\section{Circuit Mechanisms by Which Adult-Born DGCs Resolve Interference to Moderate Temporal Decay of Memory Precision}

Instantiating the circuit-based mechanisms by which adultborn DGCs modulate interference in the DG is critical to understanding how environmental risk factors for PTSD such as stress and genetic risk interact to affect pattern separation and fear generalization. In addition, a circuitbased framework will also guide strategies to improve hippocampal circuit performance in individuals at risk for developing PTSD and those who already suffer from traumarelated psychopathology (Figure 3). Here, we critique 


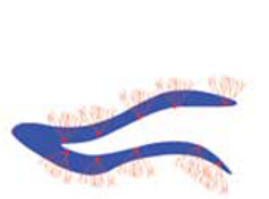

New experience
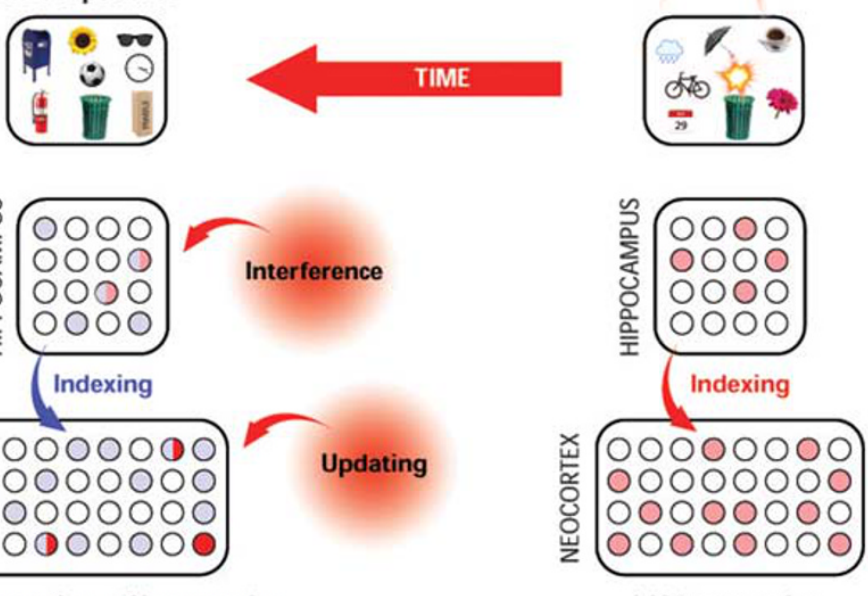

Initial representation: conjunctive
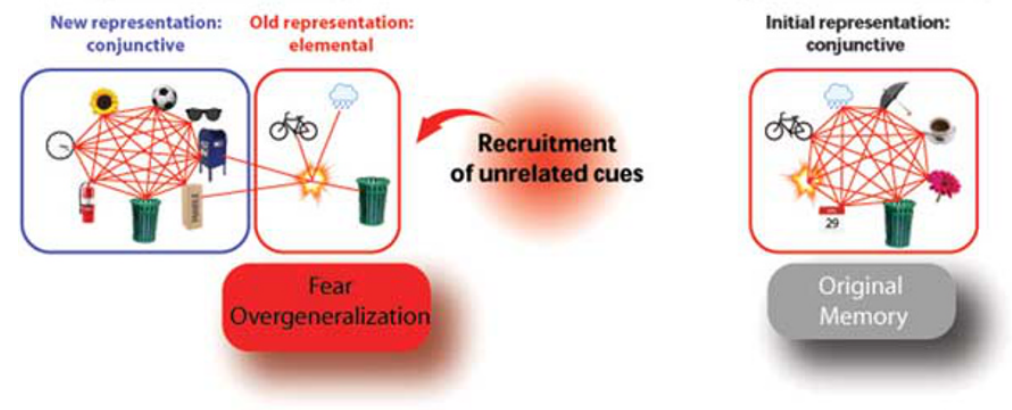

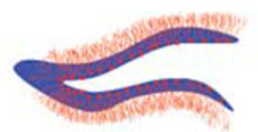

New experience
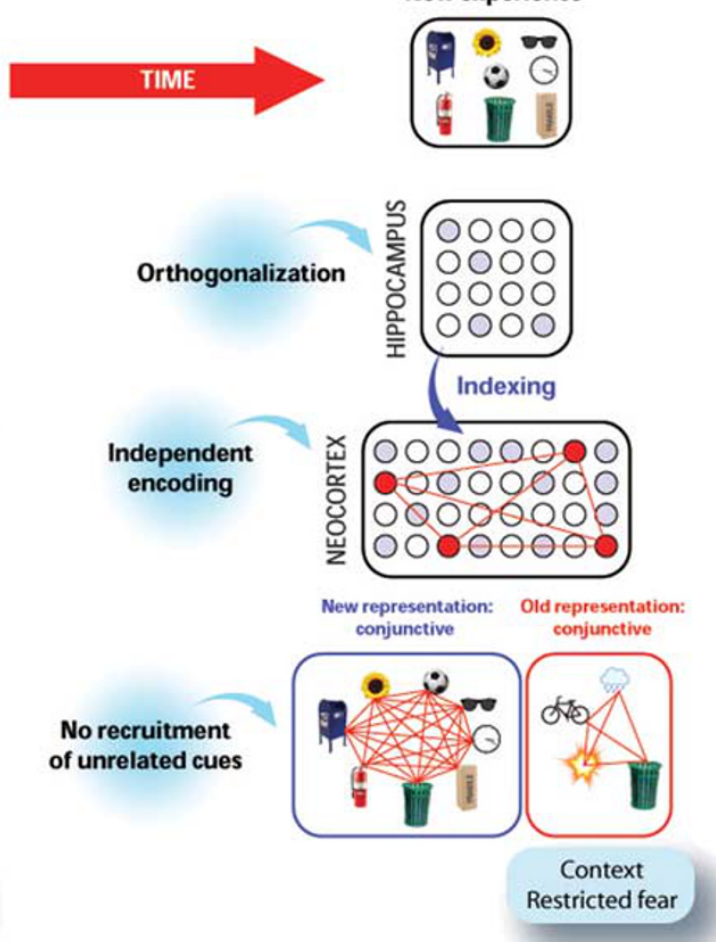

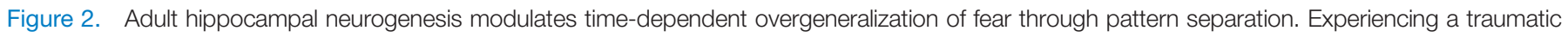

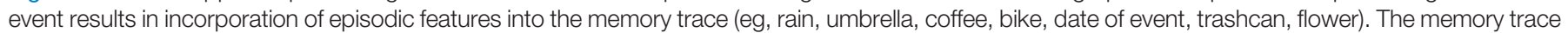

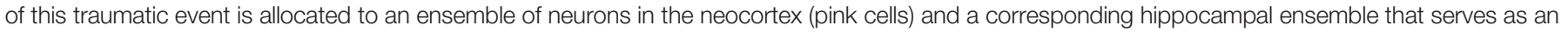

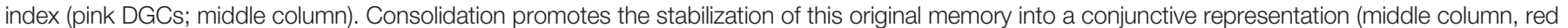

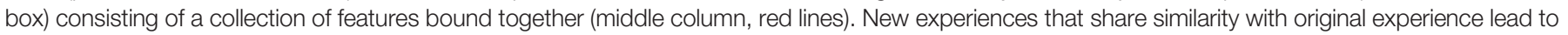

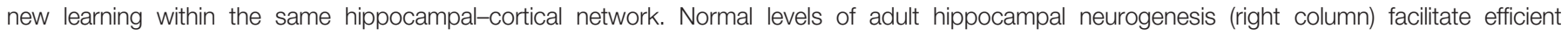

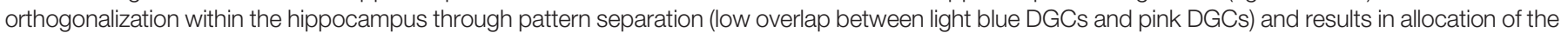

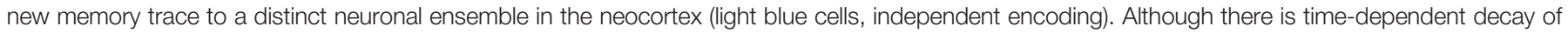

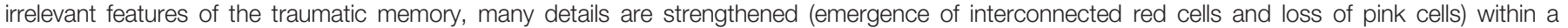

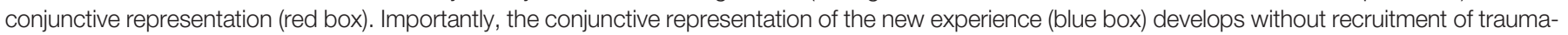

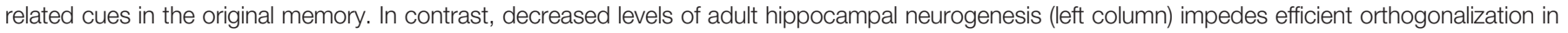

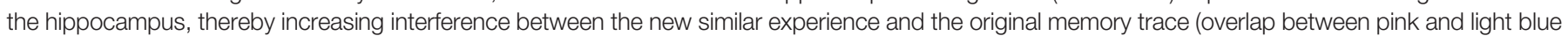

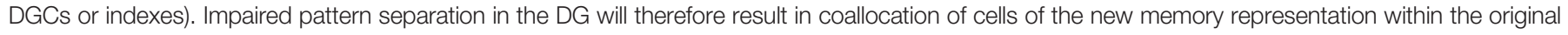

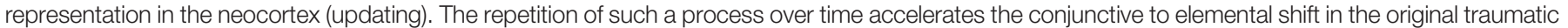

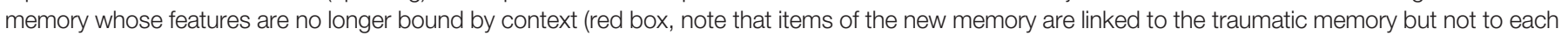

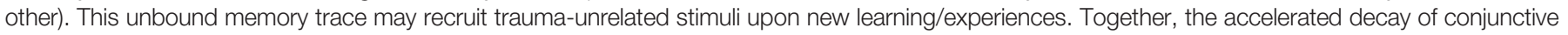
trace and incorporation of trauma-unrelated cues produces overgeneralization of fear.

evidence for putative circuit-based mechanisms by which adult-born DGCs may modulate pattern separation in the DG-CA3 circuit.

Sparseness of activity and feed-back inhibition. In vivo recordings and imaging using IEGs have shown that the DG exhibits a sparse pattern of activity (Jung and McNaughton, 1993; Chawla et al, 2005; Neunuebel and Knierim, 2012,2014). Computational models have long recognized an importance for sparse coding as conducive to decorrelation of similar inputs (McClelland and Goddard, 1996). Analysis of network-level pattern separation mechanisms in the DG and CA3 using catFISH and genetic tagging approaches suggest that the vast majority of DGCs that contribute to global remapping are the mature DGCs (Deng et al, 2013; Denny et al, 2014). In vivo recordings and calcium imaging in slices suggest that mature DGCs exhibit high input specificity (Marin-Burgin et al, 2012; Neunuebel and 


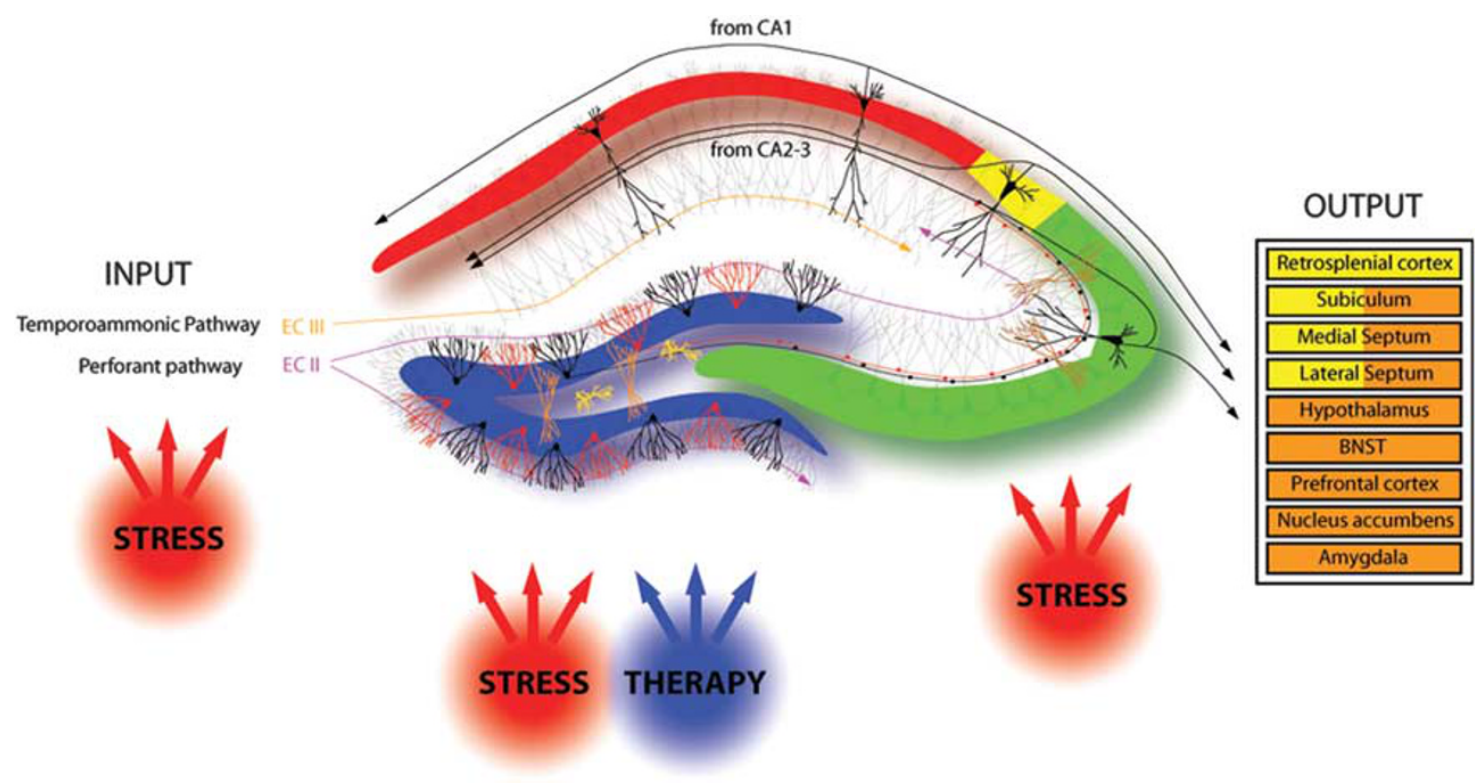

Figure 3. Stress affects adult-born DGC-dependent circuit-based mechanisms important for resolving interference. The principal layers of the hippocampus are DG (blue), CA3 (green), CA2 (yellow), and CA1 (red). The perforant path arises in the enthorinal cortex (EC) layer II and projects to the DG and CA3. The temporoammonic pathway arises in EC layer III and targets CA1. Within the DG, immature (red) and mature (black) DGCs extend mossy fibers through the hilus where they contact GABAergic interneurons (orange) and mossy cells (yellow). The activity of these interneurons and mossy cells modulates sparse activity in the DG through feed-back inhibition. Mossy fibers project to CA3 and CA2 where they form synaptic contacts with pyramidal cells (black) to mediate feed-forward excitation (FFE) and GABAergic interneurons (brown) to mediate feed-forward inhibition (FFI). CA3 pyramidal cells (black) send projections out of the hippocampus (Fimbria) to the dorsolateral septum. The same pyramidal neurons in CA3 also project to stratum radiatum of CA1 (Schaeffer collaterals). CA1 pyramidal cells (black) project to the subiculum as well as neocortical areas. Subiculum redirects the information to cortical areas and limbic regions indicated in the output box (yellow and orange indicate dorsal and ventral hippocampal outputs, respectively). These projections control emotional and cognitive processing. Stress (red arrows) decreases levels of neurogenesis in the DG and potentially affects afferent and efferent connectivity of DG-CA3 circuit. Collectively, these effects would lead to increased interference in the DG. Stimulating adult hippocampal neurogenesis or reverting stress-induced changes (blue arrows) in afferent and efferent connectivity of dentate granule neurons may maintain pattern separation functions to resolve interference and ensure context-appropriate gating of fear responses.

Knierim, 2012; Dieni et al, 2013). These observations beg the question of how adult-born DGCs influence global remapping in the DG and CA3 (Piatti et al, 2013).

We recently proposed a role for adult-born DGCs in recruiting feed-back inhibition to modulate sparseness of coding to support pattern separation in the DG (Sahay et al, 2011a; Drew et al, 2013). According to this model, increasing the number of adult-born DGCs would enhance sparseness of activity in the DG and consequently promote global remapping. To begin testing this hypothesis, we used voltage-sensitive dye imaging (VSDI) in combination with laser photostimulation and electrical stimulation of the granule cell layer (GCL) to visualize depolarization-induced spread of the VSD signal in slices from mice in which either adult hippocampal neurogenesis was blocked or increased (Ikrar et al, 2013). Interestingly, we found that genetically enhancing adult hippocampal neurogenesis resulted in a reduction in spread of activity and strength of neuronal activation in the DG, whereas blocking adult hippocampal neurogenesis produced a trend toward increased excitability of the DG ex vivo. These observations are consistent with a study showing that ablation of adult hippocampal neurogenesis diminished sparseness of activation in the DG in mice only under conditions of high interference
(Burghardt et al, 2012). Furthermore, although indirect, support for a link between adult hippocampal neurogenesis and GABAergic inhibition comes from studies showing that blockade of adult hippocampal neurogenesis decreases seizure threshold, vesicular GABA transporter VGAT, and baseline inhibitory synaptic transmission in the DG while increasing gamma burst activity (Singer et al, 2011; Lacefield et al, 2012; Schoenfeld et al, 2013; Iyengar et al, 2015). A recent study used optogenetics in slices from mice in which adult-born DGCs were labeled at different stages of maturation with channelrhodopsin to examine the extent of feed-back inhibition recruited by adult-born DGCs. The authors found adult-born DGCs recruit greater feed-back inhibition as they mature (Temprana et al, 2015). Further studies are needed to determine how feed-back inhibition recruited by adult-born DGCs influences sparseness of activity in DG and global remapping in vivo.

Experience-specific reactivation and memory persistence. Extensive studies in rodents have suggested that during the course of their maturation, adult-born DGCs acquire greater input specificity, become sensitive to GABAergic inhibition, and exhibit higher threshold for synaptic plasticity (Snyder et al, 2001; Schmidt-Hieber et al, 2004; Esposito et al, 2005; 
Laplagne et al, 2006; Saxe et al, 2006; Ge et al, 2007, 2008; Laplagne et al, 2007; Gu et al, 2012). In other words, it has been suggested that adult-born DGCs exhibit a critical period for heightened plasticity during which they may be particularly sensitive to experience-dependent modifications. In this way, neurogenesis populates the DG with units that essentially reflect the organism's experiences. Furthermore, it has been suggested that once mature, adult-born DGCs preferentially respond to inputs to which they had been previously exposed (Tashiro et al, 2007; Trouche et al, 2009; Aimone et al, 2011). Although there is no evidence directly demonstrating that young adult-born DGCs used during encoding are reactivated at remote time points when they are mature, the idea that maturation of adult-born DGCs dictates their availability for encoding (when young) and retrieval (once mature) is appealing (Figure 1). Such a mechanism may explain the growing number of loss-offunction and gain-of-function studies implicating adult hippocampal neurogenesis in maintenance of remote memories (Figure 1). Thus, the high input specificity of mature adult-born DGCs coupled with strong feed-back inhibition would maintain the hippocampal index by decreasing interference in the DG and consequently preserve the conjunctive nature of the cortical engram of the remote aversive memory (Figure 2).

Given the role of the hippocampus in replay-dependent consolidation of episodic memories (Carr et al, 2011) and evidence implicating CA3 in consolidation of contextual fear memories and ripples (Nakashiba et al, 2008, 2009), adultborn DGCs may also influence the precision of remote memories through replay. Consistent with this proposal, it has been suggested that recently tagged synapses of young excitable adult-born DGCs are more sensitive to strengthening during replay in sleep (Xia and Storm, 2012). Addressing circuit-based mechanisms by which adult-born DGCs contribute to reorganization and consolidation of cortical traces will undoubtedly impact our understanding of the role of adult hippocampal neurogenesis in maintenance of memory precision and moderation of time-dependent fear generalization.

Feed-forward inhibition in mossy fiber-CA3 circuit and contextual gating. The storage of new memories without interference with those that have been previously encoded necessitates understanding of how the DG communicates with CA3 (Figure 1). The axons of DGCs, mossy fibers, synapse onto both CA3 pyramidal neurons and GABAergic interneurons via large presynaptic terminals called mossy fiber boutons (MFBs) (Acsady et al, 1998) and numerous filopodia emanating from the MFBs, respectively. The MFB contacts with thorny excrescence-like spines of CA3 pyramidal cells mediate feed-forward excitation (FFE), whereas the disproportionately more numerous filopodial contacts with inhibitory interneurons mediate feed-forward inhibition (FFI) onto CA3 pyramidal neurons (Nicoll and Schmitz, 2005). It is thought that a balance between FFE and FFI onto CA3 neurons is required for dictating the temporal window of activation of CA3 neurons, facilitating sparse coding, and modulating excitation of the recurrent collateral circuitry of CA3; features long recognized as conducive to pattern separation-completion balance (Treves and Rolls, 1992; O'Reilly and McClelland, 1994; Bragin et al, 1995; McClelland and Goddard, 1996; Acsady and Kali, 2007; McBain, 2008; Cerasti and Treves, 2010; Torborg et al, 2010; Ikrar et al, 2013; Piatti et al, 2013). Furthermore and importantly, decreased FFI connectivity has been associated with increased time-dependent loss of memory precision and generalization of fear (Ruediger et al, 2012).

The in vivo analysis of FFI connectivity of adult-born DGCs suggests that young adult-born DGCs have significantly more filopodial contacts with GABAergic interneurons than mature DGCs (Restivo et al, 2014) (N Guo and A Sahay, unpublished observations). Although it is not known how FFI recruited by adult-born DGCs influences CA3 activity, a recent study found that loss of adult-born DGCs impaired global remapping in CA3, that is, increased overlap in CA3 neurons activated in two similar contexts (Niibori et al, 2012). Further evidence in support of a role for young adult-born DGCs in modulating remapping in CA3 comes from a study showing that silencing the output of only the mature DGCs does not affect rate remapping in CA3 (Nakashiba et al, 2012). Based on these observations, it is plausible that levels of adult hippocampal neurogenesis dictate FFI in the DG-CA3 circuit to influence pattern separation and time-dependent fear generalization.

\section{Stress Confers Vulnerability to Overgeneralization of Fear Through Changes in Adult Hippocampal Neurogenesis}

One of the most consistent brain structural abnormalities in PTSD is decreased hippocampal volume (Pitman et al, 2012). A landmark study that examined hippocampal volumes of identical twins discordant for combat exposure and PTSD found that the twins in whom one co-twin developed PTSD had smaller hippocampal volumes than the twins who did not develop PTSD. This study suggested that a smaller hippocampus confers a predisposition to stressrelated psychopathology (Gilbertson et al, 2002). Within the hippocampal formation, DG-CA3 volume is decreased in individuals with early-life stress history (Teicher et al, 2012) and in PTSD (Neylan et al, 2010; Wang et al, 2010). A recent study found impaired pattern separation in the DG of individuals with elevated depression scores (Fujii et al, 2014). Although it is not clear whether stress contributes to the higher depression scores (or depressed mood) in these individuals, these observations suggest, although indirectly, that stress alters pattern separation in the DG-CA3 circuit. How changes in hippocampal volume and DG-CA3 volumes in PTSD manifest at the level of encoding is not clear. Preclinical studies have begun to bridge this gap in our understanding by examining how stress affects adult hippocampal neurogenesis. 
Stressful experiences, as studied in rodents and primates, is known to decrease the proliferation of neural stem cells and progenitors and survival of maturation of young DGCs (Schoenfeld and Gould, 2013; Miller and Hen, 2015; Opendak and Gould, 2015; Schoenfeld and Cameron, 2015). These effects of stress on adult hippocampal neurogenesis are thought to be mediated by glucocorticoid and mineralocorticoid receptors that are expressed during distinct stages of maturation of adult-born DGCs (Garcia et al, 2004) as well as changes in glutamatergic transmission (Joels and Baram, 2009; Lupien et al, 2009; Popoli et al, 2012). Examination of how different stressors affect adult hippocampal neurogenesis along the septotemporal axis suggests increased sensitivity of the ventral DG to stress (Tanti and Belzung, 2013).

How stress affects local circuit-based mechanisms recruited by adult-born DGCs for pattern separation detailed in the previous section is poorly understood. One study examined the effects of social defeat stress on reactivation of neuronal ensembles in DG-CA3 in response to repeated exposure to a context associated with a foot-shock. The authors found that stressed mice exhibited decreased adult hippocampal neurogenesis and a reduction in reactivation of CA3 neurons, consistent with the proposal that adult-born DGCs promote reactivation of memory traces in CA3 (Denny et al, 2014). A second study found that longterm genetic ablation of adult hippocampal neurogenesis potentiated mild stress-induced activation of DGCs and CA3 neurons and increased glutamate release in CA3 (Schloesser et al, 2014). Based on these observations, we hypothesize that stress exposure disrupts FFI-FFE balance in the DG-CA3 circuit, decreases sparseness of coding, and impairs pattern separation in the DG-CA3 circuit (Guo and A Sahay, unpublished observations). Behaviorally, we predict that this would manifest as impaired discrimination and increased fear generalization under conditions of high interference.

As elevation in glucocorticoids impairs conjunctive encoding and promotes overgeneralization of fear in neutral contexts (Kaouane et al, 2012), it is plausible that stressdependent changes in adult hippocampal neurogenesis may also affect fear generalization through negative feed-back regulation of the hypothalamic-pituitary-adrenal (HPA) axis. The ventral hippocampus is known to control HPA axis responses through distinct pathways linking the subiculum and CA1 with hypothalamic nuclei and mammillary bodies (Tannenholz et al, 2014) as well as the lateral septum (Anthony et al, 2014; Strange et al, 2014). However, a role for adult hippocampal neurogenesis in regulation of the HPA axis is debated. Ablation of adult hippocampal neurogenesis in mice was found to impair negative regulation of the HPA axis in response to acute stress in some, but not all, studies (Snyder et al, 2011; Surget et al, 2011). Genetic enhancement of adult hippocampal neurogenesis did not increase the negative regulation of acute stress-induced elevation in glucocorticoids (Hill et al, 2015).
Given the differences in intrinsic and extrinsic connectivity of the hippocampus along the longitudinal axis (Bannerman et al, 2014; Strange et al, 2014), various groups have begun to address the behavioral impact of manipulating adult hippocampal neurogenesis in the dorsal and ventral DG. Using targeted $\mathrm{X}$-irradiation to ablate neurogenesis in the adult dorsal or ventral DG, it was found that adult-born neurons in the dorsal DG play a preferential role in the discrimination of a similar context from a fearful context, whereas ventral adult-born DGCs preferentially contribute to anxiety ( $\mathrm{Wu}$ and Hen, 2014). These results are consistent with previous work showing that dorsal hippocampal lesions impair contextual fear discrimination and increase fear overgeneralization (Frankland et al, 1998). Together, these observations raise the question of how pattern separationdependent computations performed by adult-born DGCs in the dorsal DG are relayed to brain regions such as the amygdala, hypothalamus, and prefrontal cortex to govern context-appropriate fear responses (Figure 3). Extensive work has emphasized the role of communication between the hippocampus and prefrontal cortex in regulating the amygdala for expression of fear (Ressler and Mayberg, 2007; Likhtik and Gordon, 2014). In addition, we propose that the connections between CA3 and the dorsolateral septum may also play a critical role in transferring pattern separationdependent computations to limbic brain regions (Luo et al, 2011) (A Besnard and A Sahay, unpublished observations). The dorsolateral septum projects to the supramammilary nucleus (SUM) (Risold and Swanson, 1997), a potent modulator of defensive behavior (exploration, freezing), arousal and stress responses, the lateral hypothalamus (Anthony et al, 2014), and ventral tegmental area (Luo et al, 2011). The primary function of the SUM is thought to bridge hippocampal-dependent cognitive operations with emotional responses mediated by the mesencephalic limbic system (amygdala, central gray, locus coeruleus, and lateral hypothalamus; Campeau and Watson, 2000; Pan and McNaughton, 2004). Although much more work is needed to establish whether the DG-CA3-CA1-prefrontal cortex or CA3-lateral septum pathway is the primary conduit for linking encoding in the DG-CA3 circuit with contextappropriate fear and stress responses, both pathways critically position $\mathrm{CA} 3$ as a node of vulnerability (Figure 3). Interestingly, long-term ablation of adult hippocampal neurogenesis was found to induce CA3 hypertrophy (Schloesser et al, 2014), reminiscent of that seen following stress (Magarinos et al, 1997; McEwen, 1999,2000; Sapolsky, 2000; McEwen et al, 2012). This raises the possibility that stress-induced decrease in adult hippocampal neurogenesis may disrupt CA3 connectivity and functions in memory processing and relaying information out of the hippocampus. Collectively, these observations begin to generate a framework to formulate how stress affects circuit-based mechanisms recruited by adult-born DGCs to modulate pattern separation and the neural pathways that link the DG-CA3 circuit with stress and fear centers in the brain. 


\section{Future Research Directions}

Stimulating and imaging adult hippocampal neurogenesis to modulate fear overgeneralization. The recent discovery that the human DG is host to hippocampal neurogenesis throughout life (Eriksson et al, 1998; Boldrini et al, 2009; Knoth et al, 2010; Spalding et al, 2013) together with preclinical studies suggest that adult hippocampal neurogenesis is a tractable therapeutic substrate for treating fear overgeneralization in PTSD. We demonstrated in a proof-ofconcept study that genetic stimulation of adult hippocampal neurogenesis is sufficient to decrease contextual fear overgeneralization and, more recently, enhance global remapping in the DG (Sahay et al, 2011b; McAvoy et al, 2014). Exercisedependent stimulation of adult hippocampal neurogenesis has been shown to decrease spatial interference in a rodent touch screen task (Creer et al, 2010) and promotes behavioral discrimination in humans (Dery et al, 2013; Voss et al, 2013). In addition, exercise also results in reorganization of afferents onto adult-born DGCs (Bergami et al, 2015). However, the molecular effectors recruited by exercise for these effects remain to be identified. Many different laboratories have begun to identify genes encoding molecular factors that govern neural stem activation, maturation, and survival of adult-born DGCs (Zhao et al, 2008; Ming and Song, 2011; Kheirbek et al, 2012b; Jessberger and Gage, 2014). Selective serotonin reuptake inhibitors (SSRIs), the current first-line therapy for PTSD, are proneurogenic and have been shown to constrain fear overgeneralization (McAvoy et al, 2015). However, adult hippocampal neurogenesis does not appear to be necessary for these effects of SSRIs on constraining fear overgeneralization, at least in middle-aged rodents (McAvoy et al, 2015). How SSRIs affect pattern separation mechanisms such as global and rate remapping in DG and CA3 remain to be addressed. Moving forward, a fundamental challenge is identifying small molecules with proneurogenic potential that may be used to rejuvenate the DG with new DGCs following stress exposure. The rediscovery of a diabetes drug, metformin, as a proneurogenic and procognitive agent and the identification of a novel proneurogenic compound that confers protection against the adverse effects of social defeat stress on mood exemplify efforts made to address this challenge (Pieper et al, 2010; Petrik et al, 2012; Wang et al, 2012; Walker et al, 2014). Another major challenge is imaging adult hippocampal neurogenesis in humans. Although volumetric studies have suggested reductions in hippocampal volume as a function of stress-related psychopathology in rodents and humans, the contributions of adult hippocampal neurogenesis are not known. Development of positron emission tomography ligands or identification of nuclear magnetic resonance (NMR) spectral signatures (Manganas et al, 2007) associated with neural stem cells or adult-born DGCs will catalyze noninvasive quantitative assessment of adult hippocampal neurogenesis in individuals at risk for stress-related psychopathology and following treatment (Kheirbek et al, 2012b; Ho et al, 2013). Although further studies are needed to refine these technologies, such approaches in combination with fMRI would also permit longitudinal assessment of how genetic risk variants interact with stress to affect adult hippocampal neurogenesis concomitantly with pattern separation in DG-CA3.

Reengineering intrinsic and extrinsic connectivity of the $D G-C A 3$ circuit. Critical to harnessing adult hippocampal neurogenesis for constraining fear overgeneralization is the need to continue to instantiate the circuit-based mechanisms by which adult-born DGCs exert their effects on computations made in DG-CA3. We predict that a circuit-based synthesis for the actions of adult-born DGCs on hippocampal-based computations and how they govern fear responses will catalyze efforts to reengineer circuits to optimize performance in disease states. Such an approach would complement the rejuvenation-based strategies described above. Specifically, the goal is to reengineer the intrinsic and extrinsic connections of DG-CA3 in such a way that the circuit performs as if there were more new adultborn DGCs. Broadly speaking, there are two complementary approaches to accomplish circuit reengineering: (1) Molecular reengineering and (2) optogenetic and electrical reengineering.

Molecular reengineering. The logic of molecular reengineering is that identification of molecular factors that specify discrete aspects of connectivity will facilitate harnessing these factors to reengineer connectivity in vivo. One example comes from studies examining how changes in intrinsic properties of neurons bias their allocation into memory traces (Han et al, 2007; Silva et al, 2009; Zhou et al, 2009; Kim et al, 2014; Yiu et al, 2014). In pioneering studies that first instantiated the cellular basis of an engram (Han et al, 2007,2009 ), it was found that neuronal recruitment into fear engrams could be biased by elevating levels of a transcription factor, cAMP response element-binding protein (CREB), or intrinsic excitability (Rogerson et al, 2014; Frankland and Josselyn, 2015). Thus, in theory, molecular control of integration of adult-born DGCs into existing memory traces may dictate interference to influence memory precision. Along these lines, unpublished work from our lab suggests that biasing integration of young adult-born DGCs before encoding slows down decay of remote contextual fear memory (McAvoy et al, 2014). A second example is the use of neurofascin to specifically modulate feed-back inhibition onto the DG by axo-axonic chandelier interneurons without affecting feed-forward inhibition. The authors took advantage of restricted expression of neurofascin in the axon initial segment that is primarily innervated by axoaxonic chandelier interneurons and found that downregulation of neurofascin decreased feed-back inhibition onto the DG to impair learning (Zitman et al, 2014). Thus, integrating molecular logic underlying DG-CA3 connectivity with an understanding of how specific features of connectivity contribute to encoding will guide chemical screens designed to identify compounds that reprogram connectivity in vivo. 
Optogenetic and electrical reengineering. A complementary effort to molecular reengineering circuits in vivo is the use of optogenetics to restore or optimize circuit performance in different disease states and under conditions of stress (Chaudhury et al, 2013; Deisseroth, 2014; Tye, 2014). A plethora of studies using optogenetics have begun to causally interrogate neural circuits in cognition and emotion (Tye and Deisseroth, 2012). Optogenetics permit controlling the activity of cell bodies such as DGCs (Kheirbek et al, 2013) or specific hippocampal sub-region afferents systems (FelixOrtiz et al, 2013; Lovett-Barron et al, 2014) or specific cell populations such as hilar GABA interneurons (AndrewsZwilling et al, 2012). Combining optogenetics with optical imaging technologies that enable in vivo imaging of cellular assemblies in awake behaving animals (Chen et al, 2013, 2015b; Ziv et al, 2013; Gunaydin et al, 2014; Jennings et al., 2015; Resendez and Stuber, 2015) will permit assessment of the interplay of different cell types in DG-CA3 microcircuits and cortical neurons in the context of encoding and reorganization of traumatic memories with passage of time. Studies showing how populations of neurons in the hippocampus and cortex can be tagged and reactivated or silenced to express and modify fear memories have brought us closer to understanding hippocampal-cortical dialogue in maintaining memory precision and valence (Liu et al, 2012; Ramirez et al, 2013; Cowansage et al, 2014; Denny et al, 2014; Redondo et al, 2014; Tanaka et al, 2014). For example, we can ask whether the reactivation of 'engram bearing cells' in the DG or 'cortical engram cells' elicit the precise recall of a remote fear memory and how the temporal decay of memory precision is changed by increasing or decreasing levels of adult hippocampal neurogenesis.

Before determining which features of connectivity need to be molecularly or optogenetically reengineered, we need to determine at high resolution how stress affects features of intrinsic and extrinsic connectivity of the DG-CA3 circuit. Viral-based tracing approaches now allow assessment of how inputs and outputs of adult-born DGCs are changed by stress (early-life or adult stressors) (Wickersham et al, 2007; Lo and Anderson, 2011; Sun et al, 2014). New imaging technologies that permit the visualization of cell type-specific connectomes (Sun et al, 2014) in intact transparent brains (Chung et al, 2013) as well as their connectivity at the ultrastructural level by expansion microscopy (Chen et al, 2015a) will also prove invaluable to these efforts. Finally, human brain imaging techniques now allow the detailed imaging of brain fiber pathways (Wedeen et al, 2012). Together, these techniques harbor potential to understand the link between structural connectivity and brain activity in relation to overgeneralization of fear.

Decoding neural activity to modify behavior. Whether pattern separation is impaired in the DG-CA3 circuit of individuals with PTSD or individuals at risk for stress-related psychopathology is yet to be determined. fMRI in combination with high-resolution structural imaging at $100 \mu \mathrm{m}$ resolution will unveil how changes in activity of the
DG-CA3 circuit correlate with structural changes in the granule cell layer and CA3 neurons (Prudent et al, 2010). By extensive recording of neural activity in distinct cell types in the rodent hippocampus, researchers have also begun to decode neural activity to predict behavior (Ziv et al, 2013). This logic has been applied in humans to develop 'affective brain-computer interfaces' that decode and rectify aberrant patterns of neuronal activity to disrupt pathological behavior (Widge et al, 2014; Grosenick et al, 2015). Deep brain stimulation is already in use for multiple indications including treatment-refractory depression (Holtzheimer and Mayberg, 2011) and has proven effective in combination with exposure therapy to improve fear extinction learning (Marin et al, 2014). It is therefore not far-fetched to envisage that closed-loop deep brain stimulation platforms will be used to predict overgeneralization of fear by detecting impaired pattern separation in the DG or aberrant activity in brain regions such as prefrontal cortex, lateral septum, or amygdala. The development of far-red shifted opsins that permit noninvasive optical inhibition of deep brain tissue (Chuong et al, 2014; Klapoetke et al, 2014) will aid in making this a reality in the future.

Modeling PTSD phenotypes in connectivity of human $D G-C A 3$ neurons. Although the study of neural circuits in rodents and humans has proven tremendously catalytic in our understanding of disorders such as PTSD, the development of reprogramming technologies that enable generation of human hippocampal neurons from skin cells (Takahashi and Yamanaka, 2006; Sanchez Alvarado and Yamanaka, 2014) has opened another avenue to link neuronal properties and connectivity with disease (McCarroll and Hyman, 2013; Hyman, 2014). The generation of DGCs (Yu et al, 2014) and CA3 neurons from skin cells of patients with PTSD will prove invaluable in assessment of cellular 'endophenotypes' at the level of basic synaptic physiology or connectivity (Wen et al, 2014). Although epigenetic marks are lost with reprogramming, disease signatures at the level of singleinduced human neurons or DG-CA3 circuits reconstructed from induced human neurons ex vivo will presumably reflect the interactions between stress and genetic risk factors of PTSD. The in vitro reconstruction of the DG-CA3 circuit with human neurons and using optical imaging and optogenetic tools to probe how properties and connectivity of DGCs and CA3 neurons from PTSD patients differ from healthy controls may enable identification of pathological changes in these neuronal populations (Garcia et al, 2012a, b; $\mathrm{Yu}$ et al, 2013). Gene editing tools that enable rapid engineering of disease mutations in human DGCs and CA3 neurons will facilitate causal assessment of genetic mutations and phenotypes (Hsu et al, 2014). The successful implementation of induced human DGCs and CA3 neuron assays is contingent upon faithful generation of DGCs and CA3 neurons and controlling for variability in patient cell lines to extract signal from noise.

Together, these different approaches represent a circuitbased approach guided by the role of adult-born DGCs in 
modulating interference and maintaining memory precision for treating overgeneralization of fear in PTSD. At the same time, some of these advances will engender debate regarding their potential for misuse (Tracey and Flower, 2014). For example, strategies to modulate interference to update memories may be used to modify memories for therapeutic impact or for detrimental effects (Redondo et al, 2014; de Lavilleon et al, 2015). These challenges notwithstanding, it is hoped that the generation of new hypotheses and innovation in basic neuroscience and stem cell medicine will ultimately lead to new treatments for PTSD.

\section{GLOSSARY}

Adult hippocampal neurogenesis: Biological process by which neural stem cells in the dentate gyrus differentiate into dentate granule neurons in the adult brain.

Semantic memory: Memory that is factual or conceptual and is devoid of spatial and temporal context (ie, decontextualized); for example, Rome is the capital of Italy.

Updating: Process by which rewriting of the original memory occurs during reactivation to integrate new information.

Consolidation: Process by which short-term memories are stabilized to generate long-term memories.

Episodic memory: Memories of events involving associations between places, events, and time (eg, memory of your family vacation from last year).

Generalization of fear: The expression of conditioned fear in response to stimuli that is similar to the conditioning stimulus. The excessive generalization of fear is referred to fear overgeneralization and is reflected in inability to restrict fear to trauma-related cues and contexts.

Time-dependent generalization: Studies in animal models show that fear memories become less precise over time and are generalized to novel contexts. This transformation of memory is thought to involve changes in associative learning mechanisms and consolidation of memories in hippocampo-cortical networks.

Proactive interference: Refers to the process by which previously learned material hampers or interferes with learning of new related material (eg, changing your email password).

Orthogonalization: Operation by which two similar input patterns are transformed into two statistically uncorrelated output patterns. This computational operation exemplifies the mechanisms by which dentate gyrus performs pattern separation in the hippocampal circuit.

Place cells: Cells that fire when an animal moves through a specific location in space. Within the hippocampus, place cells become active in specific places within the environment. For this reason they are thought to support the internal representation of the external environment.

Remapping: Emergence of distinct neural representations (eg, place cells) in response to changes in inputs to the hippocampus. Whereas rate remapping is characterized by a change in the firing rate within the same place cells, global remapping refers to the change of firing rate within different place cells.

Pattern separation: Neural mechanism by which overlap between similar inputs or memories are made more distinct, thereby minimizing interference during storage and retrieval. Pattern separation in the dentate gyrus is mediated by remapping of place cells.

Pattern completion: Neural mechanism by which a complete sequence of activity patterns is reinstated based on partial features of that pattern. Pattern completion is thought to require CA3.

Engram: Cellular and synaptic substrate of memory trace.

IEG: Immediate early genes (eg, c-fos, zif268, arc/arg3.1) are genes that are transcribed in response to neuronal activity without requiring new protein synthesis.

catFISH: Cellular compartment analysis of temporal activity by fluorescence in situ hybridization is a technique by which activation of neurons is determined based on localization of transcripts of an IEG in nuclear or cytoplasmic compartments. This technique permits assessment of extent of reactivation of neuronal ensembles over short time frames.

\section{FUNDING AND DISCLOSURE}

The authors declare no conflict of interest.

\section{ACKNOWLEDGMENTS}

The authors are supported by 2014 NARSAD Young Investigator Award, Bettencourt-Schueller Foundation and Philippe Foundation Award (to $A B$ ), the US National Institutes of Health BRAINS 1-R01MH104175, the Ellison Medical Foundation New Scholar in Aging, Whitehall Foundation, Inscopix Decode, and Harvard Stem Cell Institute Development Grants (to AS). We thank members of our laboratory for discussions and reviewers for their comments.

\section{REFERENCES}

Acheson DT, Gresack JE, Risbrough VB (2012). Hippocampal dysfunction effects on context memory: possible etiology for posttraumatic stress disorder. Neuropharmacology 62: 674-685.

Acsady L, Kali S (2007). Models, structure, function: the transformation of cortical signals in the dentate gyrus. Prog Brain Res 163: 577-599.

Acsady L, Kamondi A, Sik A, Freund T, Buzsaki G (1998). GABAergic cells are the major postsynaptic targets of mossy fibers in the rat hippocampus. J Neurosc 18: 3386-3403.

Afifi TO, Asmundson GJ, Taylor S, Jang KL (2010). The role of genes and environment on trauma exposure and posttraumatic stress disorder symptoms: a review of twin studies. Clin Psychol Rev 30: 101-112.

Aimone JB, Deng W, Gage FH (2010). Adult neurogenesis: integrating theories and separating functions. Trends Cogn Sci 14: 325-337.

Aimone JB, Deng W, Gage FH (2011). Resolving new memories: a critical look at the dentate gyrus, adult neurogenesis, and pattern separation. Neuron 70: 589-596.

Aimone JB, Li Y, Lee SW, Clemenson GD, Deng W, Gage FH (2014). Regulation and function of adult neurogenesis: from genes to cognition. Physiol Rev 94: 991-1026.

Aimone JB, Wiles J, Gage FH (2006). Potential role for adult neurogenesis in the encoding of time in new memories. Nat Neurosci 9: 723-727. 
Akers KG, Martinez-Canabal A, Restivo L, Yiu AP, De Cristofaro A, Hsiang HL et al (2014). Hippocampal neurogenesis regulates forgetting during adulthood and infancy. Science 344: 598-602.

Altman J, Das GD (1965). Autoradiographic and histological evidence of postnatal hippocampal neurogenesis in rats. J Comp Neurol 124: 319-335. First report suggesting the existence of neurogenesis in the hippocampus of adult mammals (rats) by labeling adult generated cells with Tritiated thymidine.

Alvarez RP, Chen G, Bodurka J, Kaplan R, Grillon C (2011). Phasic and sustained fear in humans elicits distinct patterns of brain activity. Neuroimage 55: 389-400.

Andrews-Zwilling Y, Gillespie AK, Kravitz AV, Nelson AB, Devidze N, Lo l et al (2012). Hilar GABAergic interneuron activity controls spatial learning and memory retrieval. PLoS One 7: e40555.

Anthony TE, Dee N, Bernard A, Lerchner W, Heintz N, Anderson DJ (2014). Control of stress-induced persistent anxiety by an extra-amygdala septohypothalamic circuit. Cell 156: 522-536.

Antoniadis EA, McDonald RJ (2000). Amygdala, hippocampus and discriminative fear conditioning to context. Behav Brain Res 108: 1-19.

Arruda-Carvalho M, Sakaguchi M, Akers KG, Josselyn SA, Frankland PW (2011). Posttraining ablation of adult-generated neurons degrades previously acquired memories. J Neurosci 31: 15113-15127. The authors ablated populations of adult-born DGCs following hippocampal learning and found that memory was impaired.

Bakker A, Kirwan CB, Miller M, Stark CE (2008). Pattern separation in the human hippocampal CA3 and dentate gyrus. Science 319: 1640-1642. First demonstration for pattern separation-like functions in the human dentate gyrus-CA3 circuit using fMRI.

Bannerman DM, Sprengel R, Sanderson DJ, McHugh SB, Rawlins JN, Monyer H et al (2014). Hippocampal synaptic plasticity, spatial memory and anxiety. Nat Rev Neurosci 15: 181-192. Discussion on the roles of the hippocampus in conflict resolution and threat appraisal.

Becker S, Wojtowicz JM (2007). A model of hippocampal neurogenesis in memory and mood disorders. Trends Cogn Sci 11: 70-76.

Bergami M, Masserdotti G, Temprana SG, Motori E, Eriksson TM, Gobel J et al (2015). A critical period for experience-dependent remodeling of adult-born neuron connectivity. Neuron 85: 710-717.

Besnard A, Caboche J, Laroche S (2012). Reconsolidation of memory: a decade of debate. Prog Neurobiol 99: 61-80.

Biedenkapp JC, Rudy JW (2007). Context preexposure prevents forgetting of a contextual fear memory: implication for regional changes in brain activation patterns associated with recent and remote memory tests. Learn Mem 14: 200203. Remote fear memories lose their context specificity over time.

Boldrini M, Underwood MD, Hen R, Rosoklija GB, Dwork AJ, John Mann J et al (2009). Antidepressants increase neural progenitor cells in the human hippocampus. Neuropsychopharmacology 34: 2376-2389.

Bragin A, Jando G, Nadasdy Z, van Landeghem M, Buzsaki G (1995). Dentate EEG spikes and associated interneuronal population bursts in the hippocampal hilar region of the rat. J Neurophysiol 73: 1691-1705.

Burghardt NS, Park EH, Hen R, Fenton AA (2012). Adult-born hippocampal neurons promote cognitive flexibility in mice. Hippocampus 22: 1795-1808. The authors used a genetic approach to show that adult-born dentate granule neurons are necessary for cognitive flexibility in an active avoidance task and for maintaining sparseness of activity in the dentate gyrus.

Cameron HA, Glover LR (2015). Adult neurogenesis: beyond learning and memory. Annu Rev Psychol 66: 53-81.

Cameron HA, Woolley CS, McEwen BS, Gould E (1993). Differentiation of newly born neurons and glia in the dentate gyrus of the adult rat. Neuroscience 56: $337-344$

Campeau S, Watson SJ Jr (2000). Connections of some auditory-responsive posterior thalamic nuclei putatively involved in activation of the hypothalamopituitary-adrenocortical axis in response to audiogenic stress in rats: an anterograde and retrograde tract tracing study combined with Fos expression. J Comp Neurol 423: 474-491.

Carr MF, Jadhav SP, Frank LM (2011). Hippocampal replay in the awake state: a potential substrate for memory consolidation and retrieval. Nat Neurosci 14: 147 $-153$.

Catani C, Jacob N, Schauer E, Kohila M, Neuner F (2008). Family violence, war, and natural disasters: a study of the effect of extreme stress on children's mental health in Sri Lanka. BMC Psychiatry 8: 33.

Cerasti E, Treves A (2010). How informative are spatial CA3 representations established by the dentate gyrus? PLoS Comput Biol 6: e1000759.

Chaudhury D, Walsh JJ, Friedman AK, Juarez B, Ku SM, Koo JW et al (2013). Rapid regulation of depression-related behaviours by control of midbrain dopamine neurons. Nature 493: 532-536.

Chawla MK, Guzowski JF, Ramirez-Amaya V, Lipa P, Hoffman KL, Marriott LK et al (2005). Sparse, environmentally selective expression of Arc RNA in the upper blade of the rodent fascia dentata by brief spatial experience. Hippocampus 15: 579-586.

Chen F, Tillberg PW, Boyden ES (2015a). Optical imaging. Expansion microscopy. Science 347: 543-548.

Chen JL, Andermann ML, Keck T, Xu NL, Ziv Y (2013). Imaging neuronal populations in behaving rodents: paradigms for studying neural circuits underlying behavior in the mammalian cortex. J Neurosci 33: 17631-17640.

Chen Y, Lin YC, Kuo TW, Knight ZA (2015b). Sensory detection of food rapidly modulates arcuate feeding circuits. Cell 160: 829-841.

Christian KM, Song H, Ming GL (2014). Functions and dysfunctions of adult hippocampal neurogenesis. Annu Rev Neurosci 37: 243-262.

Chung K, Wallace J, Kim SY, Kalyanasundaram S, Andalman AS, Davidson TJ et al (2013). Structural and molecular interrogation of intact biological systems. Nature 497: 332-337. Tissue-clearing technique that renders intact tissue transparent while preserving its structural integrity.

Chuong AS, Miri ML, Busskamp V, Matthews GA, Acker LC, Sørensen AT et al (2014). Noninvasive optical inhibition with a red-shifted microbial rhodopsin. Nat Neurosci 17: 1123-1129. Bioengineering of far-red light-sensitive opsins that allow silencing of deep brain neuron by noninvasive transcranial light application.

Clelland CD, Choi M, Romberg C, Clemenson GD Jr, Fragniere A, Tyers P et al (2009). A functional role for adult hippocampal neurogenesis in spatial pattern separation. Science 325: 210-213. Study showing that adult hippocampal neurogenesis is necessary for behavioral discrimination of overlapping spatial cues.

Colgin LL, Moser El, Moser MB (2008). Understanding memory through hippocampal remapping. Trends Neurosci 31: 469-477.

Cornelis MC, Nugent NR, Amstadter AB, Koenen KC (2010). Genetics of posttraumatic stress disorder: review and recommendations for genome-wide association studies. Curr Psychiatry Rep 12 313-326.

Cowansage KK, Shuman T, Dillingham BC, Chang A, Golshani P, Mayford M (2014). Direct reactivation of a coherent neocortical memory of context. Neuron 84: 432441. Optogenetic reactivation of 'engram-bearing' cells in the retrosplenial cortex allows context-specific reactivation of a fear memory independently of the hippocampus.

Creer DJ, Romberg C, Saksida LM, van Praag H, Bussey TJ (2010). Running enhances spatial pattern separation in mice. Proc Natl Acad Sci USA 107: 2367-2372.

Czerniawski J, Guzowski JF (2014). Acute neuroinflammation impairs context discrimination memory and disrupts pattern separation processes in hippocampus. J Neurosci 34: 12470-12480.

de Lavilleon G, Lacroix MM, Rondi-Reig L, Benchenane K (2015). Explicit memory creation during sleep demonstrates a causal role of place cells in navigation. Nat Neurosci 18: 493-495.

Deisseroth K (2014). Circuit dynamics of adaptive and maladaptive behaviour. Nature 505: 309-317

Deng W, Aimone JB, Gage FH (2010). New neurons and new memories: how does adult hippocampal neurogenesis affect learning and memory? Nat Rev Neurosci 11: 339-350.

Deng W, Mayford M, Gage FH (2013). Selection of distinct populations of dentate granule cells in response to inputs as a mechanism for pattern separation in mice. Elife 2: e00312 Discrimination of similar contexts is associated with global remapping in the DG.

Denny CA, Kheirbek MA, Alba EL, Tanaka KF, Brachman RA, Laughman KB et al (2014). Hippocampal memory traces are differentially modulated by experience, time, and adult neurogenesis. Neuron 83: 189-201. Time-dependent fear generalization is associated with decreased global remapping in DG.

Dery N, Pilgrim M, Gibala M, Gillen J, Wojtowicz JM, Macqueen G et al (2013). Adult hippocampal neurogenesis reduces memory interference in humans: opposing effects of aerobic exercise and depression. Front Neurosci 7: 66.

Deuker L, Doeller CF, Fell J, Axmacher N (2014). Human neuroimaging studies on the hippocampal CA3 region - integrating evidence for pattern separation and completion. Front Cell Neurosci 8: 64

Dias BG, Maddox SA, Klengel T, Ressler KJ (2015). Epigenetic mechanisms underlying learning and the inheritance of learned behaviors. Trends Neurosci 38: 96-107.

Dieni CV, Nietz AK, Panichi R, Wadiche Jl, Overstreet-Wadiche L (2013). Distinct determinants of sparse activation during granule cell maturation. J Neurosci 33: 19131-19142.

Drew LJ, Fusi S, Hen R (2013). Adult neurogenesis in the mammalian hippocampus: why the dentate gyrus? Learn Mem 20: 710-729.

Dudai Y (2012). The restless engram: consolidations never end. Annu Rev Neurosci 35: 227-247

Eriksson PS, Perfilieva E, Bjork-Eriksson T, Alborn AM, Nordborg C, Peterson DA et al (1998). Neurogenesis in the adult human hippocampus. Nat Med 4 : 
1313-1317. First demonstration of adult hippocampal neurogenesis in the human brain by bromodeoxyuridine (BrdU) labeling.

Ernst A, Frisen J (2015). Adult neurogenesis in humans- common and unique traits in mammals. PLoS Biol 13: e1002045.

Esposito MS, Piatti VC, Laplagne DA, Morgenstern NA, Ferrari CC, Pitossi FJ et al (2005). Neuronal differentiation in the adult hippocampus recapitulates embryonic development. J Neurosci 25: 10074-10086.

Felix-Ortiz AC, Beyeler A, Seo C, Leppla CA, Wildes CP, Tye KM (2013). BLA to VHPC inputs modulate anxiety-related behaviors. Neuron 79: 658-664.

Foa EB, Zinbarg R, Rothbaum BO (1992). Uncontrollability and unpredictability in post-traumatic stress disorder: an animal model. Psychol Bull 112: 218-238.

Frankland PW, Bontempi B (2005). The organization of recent and remote memories. Nat Rev Neuroscience 6: 119-130.

Frankland PW, Cestari V, Filipkowski RK, McDonald RJ, Silva AJ (1998). The dorsal hippocampus is essential for context discrimination but not for contextual conditioning. Behav Neurosci 112: 863-874. Dorsal hippocampal lesions prevents contextual fear discrimination learning in mice.

Frankland PW, Josselyn SA (2015). Memory allocation. Neuropsychopharmacology 40: 243.

Frankland PW, Kohler S, Josselyn SA (2013). Hippocampal neurogenesis and forgetting. Trends Neurosci 36: 497-503.

Freund J, Brandmaier AM, Lewejohann L, Kirste I, Kritzler M, Kruger A et al (2013). Emergence of individuality in genetically identical mice. Science 340: 756-759.

Freund TF, Buzsaki G (1996). Interneurons of the hippocampus. Hippocampus 6 : $347-470$

Fujii T, Saito DN, Yanaka HT, Kosaka H, Okazawa H (2014). Depressive mood modulates the anterior lateral CA1 and DG/CA3 during a pattern separation task in cognitively intact individuals: a functional MRI study. Hippocampus 24: 214-224.

Garcia A, Steiner B, Kronenberg G, Bick-Sander A, Kempermann G (2004). Agedependent expression of glucocorticoid- and mineralocorticoid receptors on neural precursor cell populations in the adult murine hippocampus. Aging Cell 3 363-371.

Garcia I, Huang L, Ung K, Arenkiel BR (2012b). Tracing synaptic connectivity onto embryonic stem cell-derived neurons. Stem Cells 30: 2140-2151.

Garcia I, Kim C, Arenkiel BR (2012a). Genetic strategies to investigate neuronal circuit properties using stem cell-derived neurons. Front Cell Neurosci 6: 59.

Garthe A, Behr J, Kempermann G (2009). Adult-generated hippocampal neurons allow the flexible use of spatially precise learning strategies. PLoS One 4: e5464 Study used a chemical agent to block adult hippocampal neurogenesis and found a role for adult-born neurons in modulating proactive interference and cognitive flexibility

Garthe A, Kempermann G (2013). An old test for new neurons: refining the Morris water maze to study the functional relevance of adult hippocampal neurogenesis. Front Neurosci 7: 63

Ge S, Sailor KA, Ming GL, Song H (2008). Synaptic integration and plasticity of new neurons in the adult hippocampus. J Physio/ 586: 3759-3765.

Ge S, Yang CH, Hsu KS, Ming GL, Song H (2007). A critical period for enhanced synaptic plasticity in newly generated neurons of the adult brain. Neuron 54: 559566. Young adult-born DGCs exhibit a critical period of enhanced synaptic plasticity in the hippocampus

Gilbert PE, Kesner RP, Lee I (2001). Dissociating hippocampal subregions: double dissociation between dentate gyrus and CA1. Hippocampus 11: 626-636. Pioneering lesion study showing that the DG is necessary for resolving spatial interference.

Gilbertson MW, Shenton ME, Ciszewski A, Kasai K, Lasko NB, Orr SP et al (2002). Smaller hippocampal volume predicts pathologic vulnerability to psychological trauma. Nat Neurosci 5: 1242-1247. Pioneering twin study suggesting that a smaller hippocampus confers a predisposition to stressrelated psychopathologies.

Gonzales RB, DeLeon Galvan CJ, Rangel YM, Claiborne BJ (2001). Distribution of thorny excrescences on CA3 pyramidal neurons in the rat hippocampus. J Comp Neurol 430: 357-368.

Goshen I (2014). The optogenetic revolution in memory research. Trends Neurosci 37: $511-522$

Goshen I, Brodsky M, Prakash R, Wallace J, Gradinaru V, Ramakrishnan C et al (2011). Dynamics of retrieval strategies for remote memories. Cell 147: 678-689. Study showing a continual role for the hippocampus in expression of remote contextual fear memory

Gottesman II, Gould TD (2003). The endophenotype concept in psychiatry: etymology and strategic intentions. Am J Psychiatry 160: 636-645.

Gray JA, McNaughton N (2000). The Neuropsychology of Anxiety: An Enquiry into the Functions of the Septo-Hippocampal System. 2nd edn. Oxford University Press: Oxford.

Grosenick L, Marshel JH, Deisseroth K (2015). Closed-loop and activity-guided optogenetic control. Neuron 86: 106-139.
Gross CT, Canteras NS (2012). The many paths to fear. Nat Rev Neurosci 13: 651-658.

Groves JO, Leslie I, Huang GJ, McHugh SB, Taylor A, Mott R et al (2013). Ablating adult neurogenesis in the rat has no effect on spatial processing: evidence from a novel pharmacogenetic model. PLoS Genet 9: e1003718.

Gu Y, Arruda-Carvalho M, Wang J, Janoschka SR, Josselyn SA, Frankland PW et al (2012). Optical controlling reveals time-dependent roles for adult-born dentate granule cells. Nat Neurosci 15: 1700-1706.

Gunaydin LA, Grosenick L, Finkelstein JC, Kauvar IV, Fenno LE, Adhikari A et al (2014). Natural neural projection dynamics underlying social behavior. Cell 157: 1535-1551.

Guzowski JF, Knierim JJ, Moser El (2004). Ensemble dynamics of hippocampal regions CA3 and CA1. Neuron 44: 581-584.

Han JH, Kushner SA, Yiu AP, Cole CJ, Matynia A, Brown RA et al (2007). Neuronal competition and selection during memory formation. Science 316: 457-460

Han JH, Kushner SA, Yiu AP, Hsiang HL, Buch T, Waisman A et al (2009). Selective erasure of a fear memory. Science 323: 1492-1496. First cellular instantiation of a memory engram.

Hardt O, Nader K, Nadel L (2013). Decay happens: the role of active forgetting in memory. Trends Cogn Sci 17: 111-120. Proposal discussing how time-dependent degradation of hippocampal memory traces influences cortical interference to promote fear overgeneralization.

Herry C, Johansen JP (2014). Encoding of fear learning and memory in distributed neuronal circuits. Nat Neurosci 17: 1644-1654.

Hill AS, Sahay A, Hen R (2015). Increasing adult hippocampal neurogenesis is sufficient to reduce anxiety and depression-like behaviors. Neuropsychopharmacology. (doi:10.1038/npp.2015.85; e-pub ahead of print).

Hinson RE (1982). Effects of UCS preexposure on excitatory and inhibitory rabbit eyelid conditioning: an associative effect of conditioned contextual stimuli. J Exp Psychol Anim Behav Process 8: 49-61.

Ho NF, Hooker JM, Sahay A, Holt DJ, Roffman JL (2013). In vivo imaging of adult human hippocampal neurogenesis: progress, pitfalls and promise. Mol Psychiatry 18: $404-416$

Holmes A, Singewald N (2013). Individual differences in recovery from traumatic fear. Trends Neurosci 36: 23-31.

Holtzheimer PE, Mayberg HS (2011). Deep brain stimulation for psychiatric disorders. Annu Rev Neurosci 34: 289-307.

Hsu PD, Lander ES, Zhang F (2014). Development and applications of CRISPRCas9 for genome engineering. Cell 157: 1262-1278.

Hyman SE (2014). Revitalizing psychiatric therapeutics. Neuropsychopharmacology 39: $220-229$

Ikrar T, Guo N, He K, Besnard A, Levinson S, Hill A et al (2013). Adult neurogenesis modifies excitability of the dentate gyrus. Front Neural Circuits 7: 204 Study showing blocking or enhancing adult hippocampal neurogenesis bidirectionally modifies excitability of the DG.

lyengar SS, LaFrancois JJ, Friedman D, Drew LJ, Denny CA, Burghardt NS et al (2015). Suppression of adult neurogenesis increases the acute effects of kainic acid. Expl Neurol 264: 135-149.

Jennings JH, Ung RL, Resendez SL, Stamatakis AM, Taylor JG, Huang $J$ et al (2015). Visualizing hypothalamic network dynamics for appetitive and consummatory behaviors. Cell 160: 516-527.

Jessberger S, Gage FH (2014). Adult neurogenesis: bridging the gap between mice and humans. Trends Cell Biol 24: 558-563.

Joels M, Baram TZ (2009). The neuro-symphony of stress. Nat Rev Neurosci 10: 459-466

Jovanovic T, Ressler KJ (2010). How the neurocircuitry and genetics of fear inhibition may inform our understanding of PTSD. Am J Psychiatry 167: 648-662.

Jung MW, McNaughton BL (1993). Spatial selectivity of unit activity in the hippocampal granular layer. Hippocampus 3: 165-182. Dentate granule cells exhibit sparse, stable, and finely tuned place fields.

Kaouane N, Porte Y, Vallee M, Brayda-Bruno L, Mons N, Calandreau L et al (2012). Glucocorticoids can induce PTSD-like memory impairments in mice. Science $\mathbf{3 3 5}$ 1510-1513.

Kaplan MS, Hinds JW (1977). Neurogenesis in the adult rat: electron microscopic analysis of light radioautographs. Science 197: 1092-1094.

Kempermann G (2008). The neurogenic reserve hypothesis: what is adult hippocampal neurogenesis good for? Trends Neurosci 31: 163-169.

Kesner RP (2013). Role of the hippocampus in mediating interference as measured by pattern separation processes. Behav Processes 93: 148-154.

Kheirbek MA, Drew LJ, Burghardt NS, Costantini DO, Tannenholz L, Ahmari SE et al (2013). Differential control of learning and anxiety along the dorsoventral axis of the dentate gyrus. Neuron 77: 955-968. Optogenetic inhibition of DGCs impairs conflict resolution in a place avoidance task 
Kheirbek MA, Klemenhagen KC, Sahay A, Hen R (2012b). Neurogenesis and generalization: a new approach to stratify and treat anxiety disorders. Nat Neurosci 15: 1613-1620.

Kheirbek MA, Tannenholz L, Hen R (2012a). NR2B-dependent plasticity of adult-born granule cells is necessary for context discrimination. J Neurosci 32: 8696-8702.

Kim J, Kwon JT, Kim HS, Josselyn SA, Han JH (2014). Memory recall and modifications by activating neurons with elevated CREB. Nat Neurosci 17: 65-72.

Kim JJ, Fanselow MS (1992). Modality-specific retrograde amnesia of fear. Science 256: 675-677.

Klapoetke NC, Murata Y, Kim SS, Pulver SR, Birdsey-Benson A, Cho YK et al (2014). Independent optical excitation of distinct neural populations. Nat Methods 11: 338-346.

Knoth R, Singec I, Ditter M, Pantazis G, Capetian P, Meyer RP et al (2010). Murine features of neurogenesis in the human hippocampus across the lifespan from 0 to 100 years. PLoS One 5: e8809.

Koenen KC, Duncan LE, Liberzon I, Ressler KJ (2013). From candidate genes to genome-wide association: the challenges and promise of posttraumatic stress disorder genetic studies. Biol Psychiatry 74: 634-636.

Kostek JA, Beck KD, Gilbertson MW, Orr SP, Pang KC, Servatius RJ et al (2014). Acquired equivalence in U.S. veterans with symptoms of posttraumatic stress: reexperiencing symptoms are associated with greater generalization. J Trauma Stress 27: 717-720.

Kuhn HG, Dickinson-Anson H, Gage FH (1996). Neurogenesis in the dentate gyrus of the adult rat: age-related decrease of neuronal progenitor proliferation. $J$ Neurosci 16: 2027-2033.

Kwapis JL, Wood MA (2014). Epigenetic mechanisms in fear conditioning: implications for treating post-traumatic stress disorder. Trends Neurosci 37: 706-720.

Lacefield CO, Itskov V, Reardon T, Hen R, Gordon JA (2012). Effects of adultgenerated granule cells on coordinated network activity in the dentate gyrus. Hippocampus 22: 106-116.

Lacy JW, Yassa MA, Stark SM, Muftuler LT, Stark CE (2011). Distinct pattern separation related transfer functions in human CA3/dentate and CA1 revealed using high-resolution fMRI and variable mnemonic similarity. Learn Mem 18: 15-18.

Laplagne DA, Esposito MS, Piatti VC, Morgenstern NA, Zhao C, van Praag $\mathrm{H}$ et al (2006). Functional convergence of neurons generated in the developing and adult hippocampus. PLoS Biol 4: e409.

Laplagne DA, Kamienkowski JE, Esposito MS, Piatti VC, Zhao C, Gage FH et al (2007). Similar GABAergic inputs in dentate granule cells born during embryonic and adult neurogenesis. Eur J Neurosci 25: 2973-2981.

Leboyer M, Bellivier F, Nosten-Bertrand M, Jouvent R, Pauls D, Mallet J (1998). Psychiatric genetics: search for phenotypes. Trends Neurosci 21: 102-105.

Lee I, Yoganarasimha D, Rao G, Knierim JJ (2004). Comparison of population coherence of place cells in hippocampal subfields CA1 and CA3. Nature 430: 456-459.

Leutgeb JK, Leutgeb S, Moser MB, Moser El (2007). Pattern separation in the dentate gyrus and CA3 of the hippocampus. Science 315: 961-966. Study showing rate remapping underlies pattern separation in the DG as rats explore parametrically morphed environments.

Leutgeb JK, Leutgeb S, Treves A, Meyer R, Barnes CA, McNaughton BL et al (2005). Progressive transformation of hippocampal neuronal representations in 'morphed' environments. Neuron 48: 345-358.

Likhtik E, Gordon JA (2014). Circuits in sync: decoding theta communication in fear and safety. Neuropsychopharmacology 39: 235-236.

Lissek S (2012). Toward an account of clinical anxiety predicated on basic, neurally mapped mechanisms of Pavlovian fear-learning: the case for conditioned overgeneralization. Depress Anxiety 29: 257-263.

Lissek S, Grillon C (2012). Conditioning Models of PTSD. The Oxford Handbook of Traumatic Disorders. Oxford University Press.

Lissek S, van Meurs B (2014). Learning models of PTSD: theoretical accounts and psychobiological evidence. Int J Psychophysiol. pii: S0167-8760(14)01647-X. doi:10.1016/j.jpsycho.2014.11.006; e-pub ahead of print.

Liu X, Ramirez S, Pang PT, Puryear CB, Govindarajan A, Deisseroth K et al (2012). Optogenetic stimulation of a hippocampal engram activates fear memory recall. Nature 484: 381-385. Cellular instantiation of fear engram in the DG.

Lo L, Anderson DJ (2011). A Cre-dependent, anterograde transsynaptic viral tracer for mapping output pathways of genetically marked neurons. Neuron 72 : 938-950.

Lovett-Barron M, Kaifosh P, Kheirbek MA, Danielson N, Zaremba JD, Reardon TR et al (2014). Dendritic inhibition in the hippocampus supports fear learning. Science 343: 857-863

Luo AH, Tahsili-Fahadan P, Wise RA, Lupica CR, Aston-Jones G (2011). Linking context with reward: a functional circuit from hippocampal CA3 to ventral tegmental area. Science 333: 353-357.
Lupien SJ, McEwen BS, Gunnar MR, Heim C (2009). Effects of stress throughout the lifespan on the brain, behaviour and cognition. Nat Rev Neurosci 10: 434-445.

Luthi A, Luscher C (2014). Pathological circuit function underlying addiction and anxiety disorders. Nat Neurosci 17: 1635-1643.

Magarinos AM, Verdugo JM, McEwen BS (1997). Chronic stress alters synaptic terminal structure in hippocampus. Proc Natl Acad Sci USA 94: 14002-14008. Study showing that chronic restraint stress alters DG-CA3 connectivity in rats.

Mahan AL, Ressler KJ (2012). Fear conditioning, synaptic plasticity and the amygdala: implications for posttraumatic stress disorder. Trends Neurosci 35: 24-35.

Malan-Muller S, Seedat S, Hemmings SM (2014). Understanding posttraumatic stress disorder: insights from the methylome. Genes Brain Behav 13: 52-68.

Manganas LN, Zhang X, Li Y, Hazel RD, Smith SD, Wagshul ME et al (2007). Magnetic resonance spectroscopy identifies neural progenitor cells in the live human brain. Science 318: 980-985. Identification of metabolic biomarkers for detection and quantification of neural stem and progenitor cells in the human brain in vivo.

Maren S, Aharonov G, Fanselow MS (1997). Neurotoxic lesions of the dorsal hippocampus and Pavlovian fear conditioning in rats. Behav Brain Res 88: 261-274

Maren S, Phan KL, Liberzon I (2013). The contextual brain: implications for fear conditioning, extinction and psychopathology. Nat Rev Neurosci 14: 417-428.

Marin MF, Camprodon JA, Dougherty DD, Milad MR (2014). Device-based brain stimulation to augment fear extinction: implications for PTSD treatment and beyond. Depress Anxiety 31: 269-278.

Marin-Burgin A, Mongiat LA, Pardi MB, Schinder AF (2012). Unique processing during a period of high excitation/inhibition balance in adult-born neurons. Science 335: 1238-1242.

Marr D (1971). Simple memory: a theory for archicortex. Philos Trans R Soc Lond B Biol Sci 262: 23-81.

McAvoy K, Russo C, Kim S, Rankin G, Sahay A (2015). Fluoxetine induces inputspecific hippocampal dendritic spine remodeling along the septotemporal axis in adulthood and middle age. Hippocampus. (doi:10.1002/hipo.22464; e-pub ahead of print).

McAvoy K, Scobie KN, Berger F, Guo N, Vega-Ramirez H, Miake-Lye S et al (2014). Rejuvenating the dentate gyrus with stage-specific expansion of adult-born neurons to enhance memory precision in adulthood and aging. Soc Neurosci. Abstracts 2014, DP09.08/DP8.

McBain CJ (2008). Differential mechanisms of transmission and plasticity at mossy fiber synapses. Prog Brain Res 169: 225-240.

McCarroll SA, Hyman SE (2013). Progress in the genetics of polygenic brain disorders: significant new challenges for neurobiology. Neuron 80: 578-587.

McClelland JL, Goddard NH (1996). Considerations arising from a complementary learning systems perspective on hippocampus and neocortex. Hippocampus 6 : 654-665. Computational model showing how sparseness in DG promotes storage of new information and separation of patterns in CA3.

McClelland JL, McNaughton BL, O'Reilly RC (1995). Why there are complementary learning systems in the hippocampus and neocortex: insights from the successes and failures of connectionist models of learning and memory. Psychol Rev 102: 419-457.

McEwen BS (1999). Stress and hippocampal plasticity. Annu Rev Neurosci 22: $105-122$.

McEwen BS (2000). Effects of adverse experiences for brain structure and function. Biol Psychiatry 48: 721-731.

McEwen BS, Eiland L, Hunter RG, Miller MM (2012). Stress and anxiety: structural plasticity and epigenetic regulation as a consequence of stress. Neuropharmacology 62: 3-12.

McHugh TJ, Jones MW, Quinn JJ, Balthasar N, Coppari R, Elmquist JK et al (2007). Dentate gyrus NMDA receptors mediate rapid pattern separation in the hippocampal network. Science 317: 94-99. Genetic disruption of perforant path-DG synaptic plasticity impairs contextual fear discrimination and remapping of place cells in CA3.

McKenzie S, Eichenbaum $\mathrm{H}$ (2011). Consolidation and reconsolidation: two lives of memories? Neuron 71: 224-233.

McNaughton BL, Morris RG (1987). Hippocampal synaptic enhancement and information storage within a distributed memory system. Trends Neurosci 10: 408-415.

Milad MR, Quirk GJ (2012). Fear extinction as a model for translational neuroscience: ten years of progress. Annu Rev Psychol 63: 129-151.

Miller BR, Hen R (2015). The current state of the neurogenic theory of depression and anxiety. Curr Opin Neurobio/ 30: 51-58.

Ming GL, Song $H$ (2011). Adult neurogenesis in the mammalian brain: significant answers and significant questions. Neuron 70: 687-702. 
Nadel L, Moscovitch M (1997). Memory consolidation, retrograde amnesia and the hippocampal complex. Curr Opin Neurobiol 7: 217-227.

Nader K, Hardt O, Lanius R (2013). Memory as a new therapeutic target. Dialogues Clin Neurosci 15: 475-486.

Nakashiba T, Buhl DL, McHugh TJ, Tonegawa S (2009). Hippocampal CA3 output is crucial for ripple-associated reactivation and consolidation of memory. Neuron 62: 781-787. Study shows that genetic blockade of CA3 output impairs consolidation of contextual fear memory and ripple-related reactivation, thereby providing evidence for continued hippocampal engagement in consolidation of cortical traces.

Nakashiba T, Cushman JD, Pelkey KA, Renaudineau S, Buhl DL, McHugh TJ et al (2012). Young dentate granule cells mediate pattern separation, whereas old granule cells facilitate pattern completion. Cell 149: 188-201.

Nakashiba T, Young JZ, McHugh TJ, Buhl DL, Tonegawa S (2008). Transgenic inhibition of synaptic transmission reveals role of CA3 output in hippocampal learning. Science 319: 1260-1264.

Nakazawa K, Quirk MC, Chitwood RA, Watanabe M, Yeckel MF, Sun LD et al (2002). Requirement for hippocampal CA3 NMDA receptors in associative memory recall. Science 297: 211-218.

Neunuebel JP, Knierim JJ (2012). Spatial firing correlates of physiologically distinct cell types of the rat dentate gyrus. J Neurosci 32: 3848-3858.

Neunuebel JP, Knierim JJ (2014). CA3 retrieves coherent representations from degraded input: direct evidence for CA3 pattern completion and dentate gyrus pattern separation. Neuron 81: 416-427. Electrophysiological recordings of place cells showing that CA3 performs pattern completion and DG pattern separation in freely moving rats

Neunuebel JP, Yoganarasimha D, Rao G, Knierim JJ (2013). Conflicts between local and global spatial frameworks dissociate neural representations of the lateral and medial entorhinal cortex. J Neurosci 33: 9246-9258.

Newman MG, Llera SJ, Erickson TM, Przeworski A, Castonguay LG (2013). Worry and generalized anxiety disorder: a review and theoretical synthesis of evidence on nature, etiology, mechanisms, and treatment. Annu Rev Clin Psychol 9: 275-297.

Neylan TC, Mueller SG, Wang Z, Metzler TJ, Lenoci M, Truran D et al (2010). Insomnia severity is associated with a decreased volume of the CA3/dentate gyrus hippocampal subfield. Biol Psychiatry 68: 494-496.

Nicoll RA, Schmitz D (2005). Synaptic plasticity at hippocampal mossy fibre synapses. Nat Rev Neurosci 6: 863-876.

Niibori Y, Yu TS, Epp JR, Akers KG, Josselyn SA, Frankland PW (2012). Suppression of adult neurogenesis impairs population coding of similar contexts in hippocampal CA3 region. Nat Commun 3: 1253 Study showing that genetic blockade of adult hippocampal neurogenesis impairs pattern separation in CA3.

O'Reilly RC, McClelland JL (1994). Hippocampal conjunctive encoding, storage, and recall: avoiding a trade-off. Hippocampus 4: 661-682.

Opendak M, Gould E (2015). Adult neurogenesis: a substrate for experiencedependent change. Trends Cogn Sci 19: 151-161.

Pan WX, McNaughton N (2004). The supramammillary area: its organization, functions and relationship to the hippocampus. Prog Neurobiol 74: 127-166.

Pan YW, Chan GC, Kuo CT, Storm DR, Xia Z (2012b). Inhibition of adult neurogenesis by inducible and targeted deletion of ERK5 mitogen-activated protein kinase specifically in adult neurogenic regions impairs contextual fear extinction and remote fear memory. J Neurosci 32: 6444-6455. Inducible deletion of ERK5 in neurogenic regions abolishes adult hippocampal neurogenesis, accelerates memory decay, and decreases cognitive flexibility.

Pan YW, Storm DR, Xia Z (2012a). The maintenance of established remote contextual fear memory requires ERK5 MAP kinase and ongoing adult neurogenesis in the hippocampus. PLoS One 7: e50455.

Parsons RG, Ressler KJ (2013). Implications of memory modulation for posttraumatic stress and fear disorders. Nat Neurosci 16: 146-153.

Petrik D, Jiang Y, Birnbaum SG, Powell CM, Kim MS, Hsieh J et al (2012). Functional and mechanistic exploration of an adult neurogenesis-promoting small molecule. FASEB J 26: 3148-3162.

Piatti VC, Ewell LA, Leutgeb JK (2013). Neurogenesis in the dentate gyrus: carrying the message or dictating the tone. Front Neurosci 7: 50.

Pickens CL, Golden SA, Adams-Deutsch T, Nair SG, Shaham Y (2009). Long-lasting incubation of conditioned fear in rats. Biol Psychiatry 65: 881-886.

Pieper AA, Xie S, Capota E, Estill SJ, Zhong J, Long JM et al (2010). Discovery of a proneurogenic, neuroprotective chemical. Cell 142: 39-51. The authors developed an in vivo screen and identified a novel, proneurogenic, neuroprotective compound that reverses age-related memory changes in hippocampus.

Pitman RK, Rasmusson AM, Koenen KC, Shin LM, Orr SP, Gilbertson MW et al (2012). Biological studies of post-traumatic stress disorder. Nat Rev Neurosci 13: 769-787.
Popoli M, Yan Z, McEwen BS, Sanacora G (2012). The stressed synapse: the impact of stress and glucocorticoids on glutamate transmission. Nat Rev Neurosci 13: 22-37.

Prudent V, Kumar A, Liu S, Wiggins G, Malaspina D, Gonen O (2010). Human hippocampal subfields in young adults at 7.0T: feasibility of imaging. Radiology 254: 900-906.

Ramirez S, Liu X, Lin PA, Suh J, Pignatelli M, Redondo RL et al (2013). Creating a false memory in the hippocampus. Science 341: 387-391.

Ramirez-Amaya V, Vazdarjanova A, Mikhael D, Rosi S, Worley PF, Barnes CA (2005). Spatial exploration-induced Arc mRNA and protein expression: evidence for selective, network-specific reactivation. J Neurosci 25: 1761-1768.

Rangel LM, Alexander AS, Aimone JB, Wiles J, Gage FH, Chiba AA et al (2014). Temporally selective contextual encoding in the dentate gyrus of the hippocampus. Nat Commun 5: 3181 Electrophysiological recordings of place cells showing that encoding of temporally separate events by DGCs is dependent on levels of adult hippocampal neurogenesis.

Rangel LM, Quinn LK, Chiba AA, Gage FH, Aimone JB (2013). A hypothesis for temporal coding of young and mature granule cells. Front Neurosci 7: 75.

Redondo RL, Kim J, Arons AL, Ramirez S, Liu X, Tonegawa S (2014). Bidirectional switch of the valence associated with a hippocampal contextual memory engram. Nature 513: 426-430. The valence of a memory supported by 'engrambearing' cells in the DG can be rewritten by optogenetic manipulation.

Resendez SL, Stuber GD (2015). In vivo calcium imaging to illuminate neurocircuit activity dynamics underlying naturalistic behavior. Neuropsychopharmacology 40 : 238-239.

Ressler KJ, Mayberg HS (2007). Targeting abnormal neural circuits in mood and anxiety disorders: from the laboratory to the clinic. Nat Neurosci 10: 1116-1124.

Restivo L, Niibori Y, Wheeler AL, Josselyn SA, Frankland PW (2014). Functional, anatomical and effective connectivity with ca3 inhibitory interneurons underlies integration of newborn dentate gyrus cells into the adult hippocampus. Soc Neurosci. Abstracts 845.28/TT66.

Risold PY, Swanson LW (1997). Connections of the rat lateral septal complex. Brain Res Brain Res Rev 24: 115-195.

Rogerson T, Cai DJ, Frank A, Sano Y, Shobe J, Lopez-Aranda MF et al (2014). Synaptic tagging during memory allocation. Nat Rev Neurosci 15: 157-169.

Rolls ET (1996). A theory of hippocampal function in memory. Hippocampus 6: 601-620.

Ruediger S, Spirig D, Donato F, Caroni P (2012). Goal-oriented searching mediated by ventral hippocampus early in trial-and-error learning. Nat Neurosci 15: 1563-1571.

Ruediger S, Vittori C, Bednarek E, Genoud C, Strata P, Sacchetti B et al (2011). Learning-related feedforward inhibitory connectivity growth required for memory precision. Nature 473: 514-518. Study suggesting a role for hippocampal mossy fiber filopodial contacts with interneurons in governing timedependent fear generalization.

Sahay A, Scobie KN, Hill AS, O'Carroll CM, Kheirbek MA, Burghardt NS et al (2011b). Increasing adult hippocampal neurogenesis is sufficient to improve pattern separation. Nature 472: 466-470. Inducible depletion of the proapoptotic gene Bax in neural progenitors in the adult brain enhances hippocampal neurogenesis and discrimination of similar, but not distinct, contexts.

Sahay A, Wilson DA, Hen R (2011a). Pattern separation: a common function for new neurons in hippocampus and olfactory bulb. Neuron 70: 582-588. Review proposing a role for adult hippocampal neurogenesis in modulating sparseness of activity in DG through feed-back inhibition.

Sanchez Alvarado A, Yamanaka S (2014). Rethinking differentiation: stem cells, regeneration, and plasticity. Cell 157: 110-119.

Sapolsky RM (2000). Glucocorticoids and hippocampal atrophy in neuropsychiatric disorders. Arch Gen Psychiatry 57: 925-935.

Satvat E, Schmidt B, Argraves M, Marrone DF, Markus EJ (2011). Changes in task demands alter the pattern of zif268 expression in the dentate gyrus. J Neurosci 31: 7163-7167. Resolving conflicting goals is associated with global remapping in the DG.

Sauerhofer E, Pamplona FA, Bedenk B, Moll GH, Dawirs RR, von Horsten S et al (2012). Generalization of contextual fear depends on associative rather than nonassociative memory components. Behav Brain Res 233: 483-493.

Saxe MD, Battaglia F, Wang JW, Malleret G, David DJ, Monckton JE et al (2006). Ablation of hippocampal neurogenesis impairs contextual fear conditioning and synaptic plasticity in the dentate gyrus. Proc Natl Acad Sci USA 103 $17501-17506$.

Schloesser RJ, Jimenez DV, Hardy NF, Paredes D, Catlow BJ, Manji HK et al (2014). Atrophy of pyramidal neurons and increased stress-induced glutamate levels in CA3 following chronic suppression of adult neurogenesis. Brain Struct Funct 219: 1139-1148.

Schmidt B, Marrone DF, Markus EJ (2012a). Disambiguating the similar: the dentate gyrus and pattern separation. Behav Brain Res 226: 56-65. 
Schmidt B, Satvat E, Argraves M, Markus EJ, Marrone DF (2012b). Cognitive demands induce selective hippocampal reorganization: arc expression in a place and response task. Hippocampus 22: 2114-2126.

Schmidt-Hieber C, Jonas P, Bischofberger J (2004). Enhanced synaptic plasticity in newly generated granule cells of the adult hippocampus. Nature 429: 184-187.

Schoenfeld TJ, Cameron HA (2015). Adult neurogenesis and mental illness. Neuropsychopharmacology 40: 113-128.

Schoenfeld TJ, Gould E (2013). Differential effects of stress and glucocorticoids on adult neurogenesis. Curr Top Behav Neurosci 15: 139-164.

Schoenfeld TJ, Rada P, Pieruzzini PR, Hsueh B, Gould E (2013). Physical exercise prevents stress-induced activation of granule neurons and enhances local inhibitory mechanisms in the dentate gyrus. J Neurosci 33: 7770-7777.

Seri B, Garcia-Verdugo JM, McEwen BS, Alvarez-Buylla A (2001). Astrocytes give rise to new neurons in the adult mammalian hippocampus. J Neurosci 21: 7153-7160.

Shin LM, Liberzon I (2010). The neurocircuitry of fear, stress, and anxiety disorders. Neuropsychopharmacology 35: 169-191.

Silva AJ, Zhou Y, Rogerson T, Shobe J, Balaji J (2009). Molecular and cellular approaches to memory allocation in neural circuits. Science 326: 391-395.

Singer BH, Gamelli AE, Fuller CL, Temme SJ, Parent JM, Murphy GG (2011). Compensatory network changes in the dentate gyrus restore long-term potentiation following ablation of neurogenesis in young-adult mice. Proc Natl Acad Sci USA 108: 5437-5442.

Skinner DM, Martin GM, Wright SL, Tomlin J, Odintsova IV, Thorpe CM et al (2014). Hippocampal spatial mapping and the acquisition of competing responses. Hippocampus 24: 396-402.

Snyder JS, Hong NS, McDonald RJ, Wojtowicz JM (2005). A role for adult neurogenesis in spatial long-term memory. Neuroscience 130: 843-852. First study showing that blockade of adult hippocampal neurogenesis decreases long-term spatial memory.

Snyder JS, Kee N, Wojtowicz JM (2001). Effects of adult neurogenesis on synaptic plasticity in the rat dentate gyrus. J Neurophysiol 85: 2423-2431.

Snyder JS, Soumier A, Brewer M, Pickel J, Cameron HA (2011). Adult hippocampal neurogenesis buffers stress responses and depressive behaviour. Nature 476: 458-461.

Spalding KL, Bergmann O, Alkass K, Bernard S, Salehpour M, Huttner HB et al (2013). Dynamics of hippocampal neurogenesis in adult humans. Cell 153: 1219-1227. Pioneering study that used retrospective Carbon-14 birth dating to demonstrate that the human DG turns over throughout life.

Sparks FT, Lehmann H, Hernandez K, Sutherland RJ (2011). Suppression of neurotoxic lesion-induced seizure activity: evidence for a permanent role for the hippocampus in contextual memory. PLoS One 6: e27426.

Squire LR, Zola-Morgan S (1991). The medial temporal lobe memory system. Science 253: 1380-1386.

Strange BA, Duggins A, Penny W, Dolan RJ, Friston KJ (2005). Information theory, novelty and hippocampal responses: unpredicted or unpredictable? Neural Netw 18: 225-230.

Strange BA, Witter MP, Lein ES, Moser El (2014). Functional organization of the hippocampal longitudinal axis. Nat Rev Neurosci 15: 655-669.

Sun Y, Nguyen AQ, Nguyen JP, Le L, Saur D, Choi J et al (2014). Cell-type-specific circuit connectivity of hippocampal CA1 revealed through Cre-dependent rabies tracing. Cell Rep 7: 269-280.

Surget A, Tanti A, Leonardo ED, Laugeray A, Rainer Q, Touma C et al (2011). Antidepressants recruit new neurons to improve stress response regulation. $\mathrm{Mol}$ Psychiatry 16: 1177-1188.

Sutherland RJ, Lehmann $\mathrm{H}$ (2011). Alternative conceptions of memory consolidation and the role of the hippocampus at the systems level in rodents. Curr Opin Neurobiol 21: 446-451.

Sutherland RJ, O'Brien J, Lehmann H (2008). Absence of systems consolidation of fear memories after dorsal, ventral, or complete hippocampal damage. Hippocampus 18: 710-718.

Swan AA, Clutton JE, Chary PK, Cook SG, Liu GG, Drew MR (2014). Characterization of the role of adult neurogenesis in touch-screen discrimination learning. Hippocampus 24: 1581-1591.

Takahashi K, Yamanaka S (2006). Induction of pluripotent stem cells from mouse embryonic and adult fibroblast cultures by defined factors. Cell 126: 663-676. First study demonstrating how mouse fibroblasts can be reprogrammed into induced pluripotent stem cells using 4 transcription factors.

Tanaka KZ, Pevzner A, Hamidi AB, Nakazawa Y, Graham J, Wiltgen BJ (2014). Cortical representations are reinstated by the hippocampus during memory retrieval. Neuron 84: 347-354.

Tannenholz L, Jimenez JC, Kheirbek MA (2014). Local and regional heterogeneity underlying hippocampal modulation of cognition and mood. Front Behav Neurosci 8: 147
Tanti A, Belzung C (2013). Neurogenesis along the septo-temporal axis of the hippocampus: are depression and the action of antidepressants region-specific? Neuroscience 252: 234-252.

Tashiro A, Makino H, Gage FH (2007). Experience-specific functional modification of the dentate gyrus through adult neurogenesis: a critical period during an immature stage. J Neurosci 27: 3252-3259. Study suggesting that mature adult-born DGCs preferentially respond to inputs that they were previously exposed to during their maturation.

Teicher MH, Anderson CM, Polcari A (2012). Childhood maltreatment is associated with reduced volume in the hippocampal subfields CA3, dentate gyrus, and subiculum. Proc Natl Acad Sci USA 109: E563-E572.

Temprana SG, Mongiat LA, Yang SM, Trinchero MF, Alvarez DD, Kropff E et al (2015). Delayed coupling to feedback inhibition during a critical period for the integration of adult-born granule cells. Neuron 85: 116-130. Causal interrogation of feed-forward and feed-back inhibition recruited by adult-born DGCs at different stages of maturation ex vivo.

Teyler TJ, DiScenna P (1986). The hippocampal memory indexing theory. Behav Neurosci 100: 147-154. Influential proposal suggesting a role for the hippocampus in indexing neocortical memory representations.

Teyler TJ, Rudy JW (2007). The hippocampal indexing theory and episodic memory: updating the index. Hippocampus 17: 1158-1169.

Torborg CL, Nakashiba T, Tonegawa S, McBain CJ (2010). Control of CA3 output by feedforward inhibition despite developmental changes in the excitationinhibition balance. J Neurosci 30: 15628-15637.

Tovote P, Fadok JP, Luthi A (2015). Neuronal circuits for fear and anxiety. Nat Rev Neurosci 16: 317-331.

Tracey I, Flower R (2014). The warrior in the machine: neuroscience goes to war. Nat Rev Neurosci 15: 825-834.

Treves A, Rolls ET (1992). Computational constraints suggest the need for two distinct input systems to the hippocampal CA3 network. Hippocampus 2: 189-199.

Tronel S, Belnoue L, Grosjean N, Revest JM, Piazza PV, Koehl M et al (2012). Adultborn neurons are necessary for extended contextual discrimination. Hippocampus 22: 292-298.

Trouche S, Bontempi B, Roullet P, Rampon C (2009). Recruitment of adultgenerated neurons into functional hippocampal networks contributes to updating and strengthening of spatial memory. Proc Natl Acad Sci USA 106: 5919-5924.

Tye KM (2014). Neural circuit reprogramming: a new paradigm for treating neuropsychiatric disease? Neuron 83: 1259-1261.

Tye KM, Deisseroth K (2012). Optogenetic investigation of neural circuits underlying brain disease in animal models. Nat Rev Neurosci 13: 251-266.

Vanni-Mercier G, Mauguiere F, Isnard J, Dreher JC (2009). The hippocampus codes the uncertainty of cue-outcome associations: an intracranial electrophysiological study in humans. J Neurosci 29: 5287-5294. Electrophysiological recordings in humans suggesting a role for the hippocampus in computing uncertainty signals for reward outcome probabilities.

Vazdarjanova A, Guzowski JF (2004). Differences in hippocampal neuronal population responses to modifications of an environmental context: evidence for distinct, yet complementary, functions of CA3 and CA1 ensembles. J Neurosci 24: 6489-6496. Pioneering study demonstrating using IEG-based cellular imaging approaches that global remapping occurs in CA3

Voss MW, Vivar C, Kramer AF, van Praag H (2013). Bridging animal and human models of exercise-induced brain plasticity. Trends Cogn Sci 17: 525-544.

Walker AK, Rivera PD, Wang Q, Chuang JC, Tran S, Osborne-Lawrence S et al (2014). The P7C3 class of neuroprotective compounds exerts antidepressant efficacy in mice by increasing hippocampal neurogenesis. Mol Psychiatry 20: 500-508

Wang J, Gallagher D, DeVito LM, Cancino Gl, Tsui D, He L et al (2012). Metformin activates an atypical PKC-CBP pathway to promote neurogenesis and enhance spatial memory formation. Cell Stem Cell 11: 23-35.

Wang SH, Morris RG (2010). Hippocampal-neocortical interactions in memory formation, consolidation, and reconsolidation. Annu Rev Psychol 61: 49-79 C41-44.

Wang SH, Teixeira CM, Wheeler AL, Frankland PW (2009). The precision of remote context memories does not require the hippocampus. Nat Neurosci 12: 253-255.

Wang W, Pan YW, Zou J, Li T, Abel GM, Palmiter RD et al (2014). Genetic activation of ERK5 MAP kinase enhances adult neurogenesis and extends hippocampusdependent long-term memory. J Neurosci 34: 2130-2147. Inducible expression of a constitutively active ERK5 throughout adult-born DGC lineage, enhances cognitive flexibility, and extends hippocampal memory.

Wang Z, Neylan TC, Mueller SG, Lenoci M, Truran D, Marmar CR et al (2010). Magnetic resonance imaging of hippocampal subfields in posttraumatic stress disorder. Arch Gen Psychiatry 67: 296-303. Structural imaging study showing reduced DG-CA3 volumes in individuals with PTSD. 
Wedeen VJ, Rosene DL, Wang R, Dai G, Mortazavi F, Hagmann P et al (2012). The geometric structure of the brain fiber pathways. Science 335: 1628-1634.

Wen Z, Nguyen HN, Guo Z, Lalli MA, Wang X, Su Y et al (2014). Synaptic dysregulation in a human iPS cell model of mental disorders. Nature 515: 414-418.

Wickersham IR, Lyon DC, Barnard RJ, Mori T, Finke S, Conzelmann KK et al (2007). Monosynaptic restriction of transsynaptic tracing from single, genetically targeted neurons. Neuron 53: 639-647.

Widge AS, Dougherty DD, Moritz CT (2014). Affective brain-computer interfaces as enabling technology for responsive psychiatric stimulation. Brain Comput Interfaces (Abingdon) 1: 126-136.

Wiltgen BJ, Silva AJ (2007). Memory for context becomes less specific with time. Learn Mem 14: 313-317. Contextual fear memories generalize to novel, distinct contexts with time.

Wiltgen BJ, Zhou M, Cai Y, Balaji J, Karlsson MG, Parivash SN et al (2010). The hippocampus plays a selective role in the retrieval of detailed contextual memories. Curr Biol 20: 1336-1344.

Winocur G, Becker S, Luu P, Rosenzweig S, Wojtowicz JM (2012). Adult hippocampal neurogenesis and memory interference. Behav Brain Res 227: 464-469.

Winocur G, Moscovitch M, Sekeres M (2007). Memory consolidation or transformation: context manipulation and hippocampal representations of memory. Nat Neurosci 10: 555-557.

Wiskott L, Rasch MJ, Kempermann G (2006). A functional hypothesis for adult hippocampal neurogenesis: avoidance of catastrophic interference in the dentate gyrus. Hippocampus 16: 329-343.

Wojtowicz JM, Askew ML, Winocur G (2008). The effects of running and of inhibiting adult neurogenesis on learning and memory in rats. Eur $J$ Neurosci 27: 1494-1502.

Wu MV, Hen R (2014). Functional dissociation of adult-born neurons along the dorsoventral axis of the dentate gyrus. Hippocampus 24: 751-761.

Xia Z, Storm DR (2012). Role of signal transduction crosstalk between adenylyl cyclase and MAP kinase in hippocampus-dependent memory. Learn Mem 19: 369-374.

Yassa MA, Stark CE (2011). Pattern separation in the hippocampus. Trends Neurosci 34: 515-525.
Yehuda R, Daskalakis NP, Lehrner A, Desarnaud F, Bader HN, Makotkine I et al (2014). Influences of maternal and paternal PTSD on epigenetic regulation of the glucocorticoid receptor gene in Holocaust survivor offspring. Am J Psychiatry 171: 872-880.

Yehuda R, LeDoux J (2007). Response variation following trauma: a translational neuroscience approach to understanding PTSD. Neuron 56: 19-32.

Yiu AP, Mercaldo V, Yan C, Richards B, Rashid AJ, Hsiang HL et al (2014). Neurons are recruited to a memory trace based on relative neuronal excitability immediately before training. Neuron 83: 722-735.

Yu DX, Di Giorgio FP, Yao J, Marchetto MC, Brennand K, Wright R et al (2014). Modeling hippocampal neurogenesis using human pluripotent stem cells. Stem Cell Rep 2: 295-310.

Yu DX, Marchetto MC, Gage FH (2013). Therapeutic translation of iPSCs for treating neurological disease. Cell Stem Cell 12: 678-688.

Zhang CL, Zou Y, He W, Gage FH, Evans RM (2008). A role for adult TLX-positive neural stem cells in learning and behaviour. Nature 451: 1004-1007.

Zhang J, Ji F, Liu Y, Lei X, Li H, Ji G et al (2014). Ezh2 regulates adult hippocampal neurogenesis and memory. J Neurosci 34: 5184-5199.

Zhao C, Deng W, Gage FH (2008). Mechanisms and functional implications of adult neurogenesis. Cell 132: 645-660.

Zhou Y, Won J, Karlsson MG, Zhou M, Rogerson T, Balaji J et al (2009). CREB regulates excitability and the allocation of memory to subsets of neurons in the amygdala. Nat Neurosci 12: 1438-1443.

Zitman FM, Lucas M, Trinks S, Grosse-Ophoff L, Kriebel M, Volkmer H et al (2014). Dentate gyrus local circuit is implicated in learning under stress-a role for neurofascin. Mol Neurobiol. (e-pub ahead of print).

Ziv Y, Burns LD, Cocker ED, Hamel EO, Ghosh KK, Kitch LJ et al (2013). Long-term dynamics of CA1 hippocampal place codes. Nat Neurosci 16: 264-266. Chronic calcium imaging in CA1 of freely moving mice allows decoding of place cells activity over time.

Zola-Morgan SM, Squire LR (1990). The primate hippocampal formation: evidence for a time-limited role in memory storage. Science 250: 288-290.

Zovkic IB, Sweatt JD (2013). Epigenetic mechanisms in learned fear: implications for PTSD. Neuropsychopharmacology 38: 77-93. 